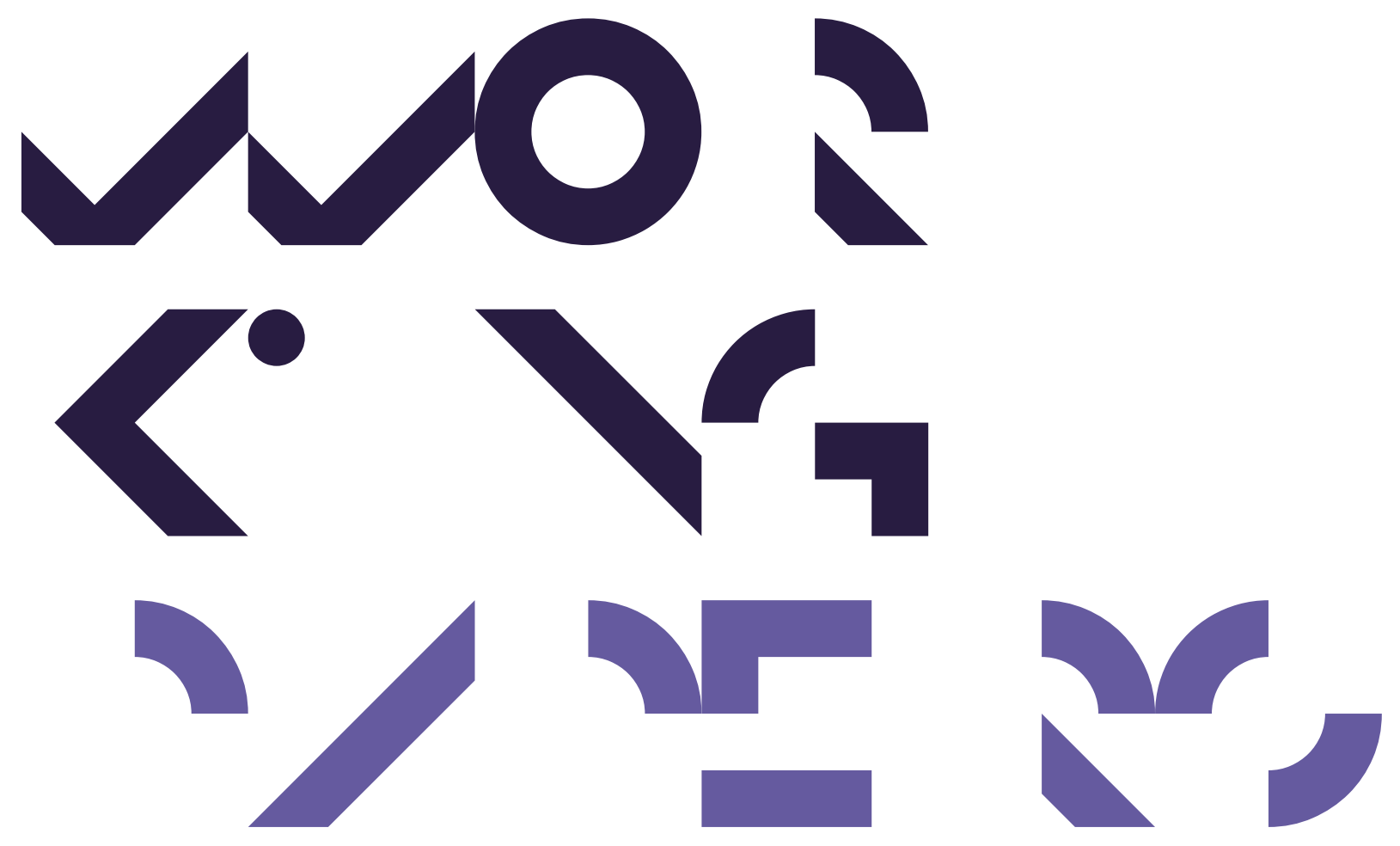

Economics Working Papers

2017-9

Superstar Exporters: An Empirical Investigation of Strategic Interactions in Danish Export Markets

Federico Ciliberto and Ina C. Jäkel 


\title{
Superstar Exporters: An Empirical Investigation of Strategic Interactions in Danish Export Markets*
}

\author{
Federico Ciliberto ${ }^{\dagger} \quad$ Ina C. Jäkel ${ }^{\ddagger}$
}

September 15, 2017

\begin{abstract}
In many countries, exports are highly concentrated among a few "superstar" firms. We estimate the export decisions of superstar firms as the result of a complete information, simultaneous, discrete choice, static entry game. We employ a dataset on the universe of Danish trade transactions by firm, product and destination. We also obtain detailed information on applied, preferential tariff protection from the MAcMap-HS6 database. We find evidence of strong negative competitive effects of entry: in the absence of strategic competitive effects, firms would be 54.3 percentage points more likely to export to a given market. Next, we run two counterfactual exercises. We show that failing to account for the strategic interaction among superstar exporters leads to: ( $i$ ) overstating the probability that firms would start exporting to a market following tariff elimination by 8 percentage points; and, (ii) overstating the probability that firms would stop exporting to a market if tariffs were imposed by 7.5 percentage points. We also show that competitive effects vary across export markets and competitors. This heterogeneity in the competitive effects implies that there exist multiple equilibria, both in the identity and in the number of firms.
\end{abstract}

Keywords: Export participation - Strategic interaction · Multiple equilibria - Trade policy. JEL codes: F12, F14, L13.

${ }^{*}$ We thank conference and seminar participants at the Danish International Economics Workshop (Aarhus Unversity), the 8th International ADI Conference (Copenhagen University), the Aarhus-Kiel Christmas Workshop, and the University of Bochum for their constructive feedback.

${ }^{\dagger}$ Department of Economics, University of Virginia, Charlottesville, VA 22904-4182. E-mail: fc3p@eservices.virginia.edu. Tel: +1 4349246755.

$\ddagger$ Department of Economics and Business Economics, Aarhus University, Fuglesangs Allé 4, 8210 Aarhus V, Denmark. E-mail: inaj@econ.au.dk. Tel.: +45 871 65195. Ina C. Jäkel gratefully acknowledges financial support from Danmarks Frie Forskningsfond (DFF) and the Tuborg Foundation. 


\section{Introduction}

In many countries, exports are highly concentrated among a few "superstar" firms (Freund \& Pierola, 2015). For example, in the United States, the top 1 percent of exporters accounted for 80 percent of total exports in 2000 (Bernard et al., 2007). In Denmark, the top 1 percent of exporters accounted for 47 percent of total exports in 2007, and, on average, the top 5 firms in an industry accounted for 80 percent of exports. Motivated by these observations, we conduct an empirical analysis of export decisions where superstar firms behave strategically. Then, we use our estimated model to run a counterfactual exercise and investigate the effect of a tariff policy change on the export decisions of the superstar firms.

Our main objective is to contribute to the understanding of the role of superstars in international trade. Despite the dominance of a few large exporters in world trade, trade models have traditionally relied on a monopolistic competition setting, where firms are infinitesimal in scale, take prices as given, and compete non-strategically (see Neary, 2010). Recently, trade economists have been developing new theoretical models with oligopolistic markets, i.e., markets where only a few dominant firms compete. ${ }^{1}$ These new models feature firms that behave strategically, so that the decision of each firm is influenced by the decisions of its competitors. However, this literature remains to date mostly theoretical, and the prediction that the export decisions of oligopolistic firms are interdependent has not been tested empirically. In this paper, we aim to fill this gap in the literature.

To develop our analysis, we apply the econometric approach in Ciliberto \& Tamer (2009) to model the export decisions of firms as a complete information, simultaneous, discrete choice, static, entry game. Compared to previous studies on firms' export decisions, the unit of analysis is not the individual firm but the market, defined as an industry-destination combination; and the outcome of interest is the market equilibrium, defined as a vector of market-specific participation decisions of all Danish superstars. The key assumption is that a firm enters an export market only if it makes non-negative profits. To solve the game we use the notion of Nash equilibrium, whereby all firms are maximizing profits and no firm

\footnotetext{
${ }^{1}$ See, in particular, Eaton et al. (2012), Bekkers \& Francois (2013), Parenti (2013), Koska \& Stähler (2014) and Neary (2015). There is an earlier literature of oligopolistic markets and trade building on Brander (1981) and Brander \& Krugman (1983), but this literature has arguably remained much less influential than either the perfect competition or monopolistic competition settings; see Neary (2010) for a review.
} 
would want to unilaterally change its participation decision. In a discrete choice setting, this leads to a set of moment inequalities, which we estimate using Ciliberto \& Tamer (2009).

The main parameters of interest in our empirical model are the effects of the strategic interaction, or "competitive effects", which capture the effect that a firm's export decision has on its competitors' export decisions. Standard models of oligopoly predict a negative effect, as a competitor's market entry reduces other firms' profits, and thus entry. However, positive effects are possible in the presence of positive externalities including informational spillovers, which are particularly important in an international trade context. ${ }^{2}$ While the earlier literature on entry games assumes, for identification reasons, that this competitive effect is known to be negative (see Bresnahan \& Reiss (1990) and Berry (1992)), the econometric approach of Ciliberto \& Tamer (2009) allows for both positive and negative effects.

We use two datasets in our analysis. First, we employ a register database provided by Denmark Statistics, which covers the universe of trade transactions by firm, product and destination. This database allows us to identify superstar exporters and to empirically model their export decisions. Second, we obtain detailed information on applied, preferential tariff protection in 2007 from the third version of the MAcMap-HS6 database (Guimbard et al., 2012). The database covers tariffs by product and destination and can therefore be merged with the register database. We use these data to run our policy experiments.

We find evidence of strong negative competitive effects. On average, in the absence of competitive effects superstar firms would be 54.3 percentage points more like to export into a market. This implies that the presence of other Danish competitors in a specific export market significantly reduces profits and hence export participation. This finding has important implications for trade policy. As trade is liberalized, positive effects on profits are counter-balanced by negative effects due to competitor entry. Estimates that do not take these competitive effects into account will therefore overestimate the entry response due to trade liberalization.

\footnotetext{
${ }^{2}$ The literature on export spillovers shows that firms are more likely to start exporting to markets already served by other domestic firms; see inter alia Aitken et al. (1997) and Koenig et al. (2010). Choquette \& Meinen (2015) present evidence on positive export spillovers based on Danish data. We differ from this literature in two respects. First, we focus on superstar exporters, i.e., the set of firms for which strategic interactions may be relevant. Second, we estimate an equilibrium model for the market outcome, which allows us to explicitly take into account the simultaneity of export decisions.
} 
We run two counterfactual exercises in order to quantify these biases. First, we simulate the effects of eliminating tariffs in markets where tariffs are imposed. Secondly, we simulate the effects of introducing tariffs in markets where trade is duty-free. In both exercises, we compute the new equilibria for the export markets, and compare results with and without competitive effects between firms. In our first counterfactual exercise, we find that eliminating tariffs would increase the probability that at least one firm exports into a given market by 30.5 percent. In the absence of competitive effects, the same probability would increase by 38.5 percent. Thus, failing to account for the strategic interaction among superstar exporters will lead to overstating by 8 percentage points the probability that at least one firm exports following tariff elimination. In our second counterfactual exercise, we find that introducing tariffs would decrease the probability that at least one firm exports into that market by 37.4 percent. In the absence of competitive effects, this probability would increase by 44.9 percent. In sum, the effect of changing tariffs would be overestimated in a model that does not allow for the strategic interaction among firms.

Finally, we show that the competitive effects vary across firms and destinations: they are smaller, the bigger the GDP of the destination country, and they are larger the more geographically distant the destination country. Thus, competitive effects are more important in destinations which are harder to enter. We also find that a given superstar's effect on its competitors' export decisions depends on the number of other countries where the firm is exporting a variety. The larger this number, the more likely it is for its competitor to export to the given destination. Firms that serve many export markets may have a high visibility to their competitors, resulting in a larger potential for informational spillovers. Another explanation is that firms that serve a large number of other export markets may compete less aggressively in a given destination, because each destination has a lower importance for their overall exports. Relatedly, these heterogeneous competitive effects imply that there exist multiple equilibria, both in the identity and in the number of firms. Thus, the flexible methodology proposed by Tamer (2003) and Ciliberto and Tamer (2009) is appropriate to study the strategic behavior of superstar exporters.

Our research contributes to two strands of the empirical international trade literature. First, we contribute to the literature on the determinants of firms' export market decisions. 
In highly influential work, Roberts \& Tybout (1997), Bernard \& Jensen (2004), Das et al. (2007) have investigated the role of firm characteristics (such as productivity, size, and previous export experience) as determinants of firms' export decisions. These papers have treated observations on individual firms as independent. In contrast, we model the export decision as the outcome of oligopolistic strategic interactions. Second, we contribute to the growing literature on the importance of large firms for aggregate fluctuations (di Giovanni \& Levchenko, 2012) and on the role of superstar exporters as drivers of export patterns and revealed comparative advantage (Freund \& Pierola, 2015). We augment this literature by modeling the strategic interaction between large exporters in their export market choices.

We also contribute to the empirical trade literature by studying the policy implications of strategic interaction between superstar exporters. Here, we build on previous studies that have found positive effects of tariff liberalization on export participation (Bernard et al., 2011; Buono \& Lalanne, 2012). We extend this line of work by showing that the direct (positive) effect on profits as trade is liberalized is partly offset by an indirect (negative) effect resulting from the entry of competitors. ${ }^{3}$

Finally, we contribute to the empirical literature on models with moment inequalities, which has been steadily growing in the last few years. In particular, this literature includes studies on peer effects in fertility decisions (Ciliberto et al., 2016), substance abuse treatment clinics' location choice (Cohen et al., 2013), the decision of churches to provide child care services (Rennhoff \& Owens, 2012), the nature of bargaining between hospitals and insurers in the United States (Ho \& Lee, 2017), the hospital referral patterns of doctors in the United States (Ho \& Pakes, 2014), and the diffusion of Walmart (Jia, 2008; Holmes, 2011). Our paper complements Morales et al. (2017) and Dickstein \& Morales (2016). Both of these two papers use moment inequality conditions, the first one to show that having similarities with a prior export destination in geographic location, language, and income per capital jointly reduces the cost of foreign market entry; the second one to show that larger firms possess better knowledge of market conditions in foreign countries. The key difference between our paper and these two papers is that in our paper firms behave strategically when deciding

\footnotetext{
${ }^{3}$ An earlier theoretical literature starting with Brander \& Spencer (1985) analyzes how governments may use strategic trade policy to shift profits from foreign to domestic firms. Here, instead, we only consider the effects of trade policy on the strategic interaction between domestic firms.
} 
whether to export to a country, while in Morales et al. (2017) and Dickstein \& Morales (2016) the firms are assumed to behave as monopolistically competitive firms.

This paper proceeds as follows. Section 2 presents the empirical approach. Section 3 introduces the data and discusses observed market structures. Sections 4 and 5 present results from single agent (probit) estimations and the equilibrium model, respectively. In Section 6 we do comparative statics exercises to measure the effect of changes in the exogenous variables on the export propensity of the firms. In Section 7 we perform our two counterfactual exercises where we eliminate tariffs in markets that have positive tariffs, and we introduce tariffs in markets that do not have tariffs. Section 8 concludes.

\section{Empirical Model of Export Decisions}

We build on previous models on export market entry (see, e.g., Roberts \& Tybout, 1997), with the key innovation being that we allow for strategic interaction among superstar exporters. Our unit of observation is a market and the outcome of interest is the market equilibrium, i.e., the vector of export decisions of all potential entrants in the market. This is in contrast to the previous literature on firms' export market choices, which considers each firm's export decision in isolation.

We define a market $m=1, \ldots, N_{m}$ as a combination of an industry $I=1, \ldots, N_{I}$ and country of destination $c=1, \ldots, N_{c}$. For example, $I$ might be the chocolate and confectionery industry, while $c$ could be Germany. More detail on the market definition is provided in Section 3.1.

A firm is a potential entrant in market $m$ if it serves industry $I$ in at least one of the export destinations. Thus, firms that do not export are not included in the analysis, and some firms may serve more than one industry. Formally, in each market $m$, there is a set of $i=1, \ldots K_{m}$ potential Danish entrants. To ease exposition, and following the terminology in the trade literature, we refer to a firm within an industry as a 'variety'.

A market structure is the vector of equilibrium export decisions $\mathbf{y}_{m}=\left(y_{1 m}, \ldots y_{K_{m}, m}\right)$, where $y_{i m}$ is equal to 1 if variety $i$ serves market $m$, and it is equal to 0 otherwise. Notice that only Danish varieties are included because we do not observe the export decisions of 
foreign or third country competitors. This modeling approach is driven by data availability, but can be motivated by the work of Feenstra et al. (2014), who show that products from different origins (e.g., Denmark vs. the United States) are imperfect substitutes. ${ }^{4}$

Following Roberts \& Tybout (1997), the profits of the exporters are modeled with a reduced-form expression of exogenous competitor and market characteristics that are observable to producers. ${ }^{5}$ The profit of variety $i$ in market $m$ is given as follows:

$$
\pi_{i m}=\mathbf{X}_{m}^{\prime} \boldsymbol{\alpha}+\mathbf{Z}_{i m}^{\prime} \boldsymbol{\beta}+\sum_{j \neq i} y_{j m} \delta_{1}+\sum_{j \neq i} y_{j m} \cdot Z_{j l m} \cdot \delta_{l}+\sum_{j \neq i} y_{j m} \cdot X_{h m} \cdot \delta_{h}+\epsilon_{i m}
$$

for $i, j \in I$. In this profit function, $\mathbf{X}_{m}=\left(X_{m, 1}, \ldots, X_{m, N_{X}}\right)$ is a vector of $N_{X}$ market-specific variables, for example the geographical distance from Denmark. $\mathbf{Z}_{i m}=\left(Z_{i m, 1}, \ldots Z_{i m, N_{Z}}\right)$ is a vector of $N_{Z}$ competitor- and market-specific variables, for example the number of other destinations to which variety $i$ is exported. $\boldsymbol{\alpha}=\left(\alpha_{1}, \ldots \alpha_{N_{X}}\right)$ and $\boldsymbol{\beta}=\left(\beta_{1}, \ldots \beta_{N_{Z}}\right)$ are the corresponding parameter vectors to estimate.

$\epsilon_{i m}$ is unobserved by the econometrician, but we maintain that it is observed by all players in market $m$. Thus, we model the decision of a superstar firm to export its variety $i \in I$ to destination $c$ in the context of a complete information, simultaneous move, static discrete choice game. This is the same modeling assumption made in Bresnahan \& Reiss (1990), Berry (1992), Mazzeo (2002), Tamer (2003) and Ciliberto \& Tamer (2009). We maintain that in each market firms are in a long-run equilibrium.

The key parameters of interest that capture the effect that a firm's export market presence has on its competitors' profits are $\delta_{1}, \delta_{l}$, and $\delta_{h}$. The parameter $\delta_{1}$ captures the constant effect that a firm's presence has on the profits of its competitors. $l$ is one of the variables in $\mathbf{Z}_{i m}$, and the parameter $\delta_{l}$ measures whether the competitive effects change with changes in this firm-specific variable. Finally, $h$ denotes one of the variables in $\mathbf{X}_{m}$ and the parameter $\delta_{h}$ captures how competitive effects vary across markets with changes in this market-specific

\footnotetext{
${ }^{4}$ In particular, Feenstra et al. (2014) find that the median estimate of the "micro" elasticity of substitution between different sources of imports stands at 3.24, while the "macro" elasticity between imports and domestic production is typically lower.

${ }^{5}$ An important difference between our work and Roberts \& Tybout (1997) is that they look at a dynamic model of (single firm) entry, while we look at a static model of strategic entry with multiple firms. Because they use a panel dataset and estimate a dynamic model, Roberts \& Tybout (1997) can control for whether a firm was already exporting the period before, and use that variable to estimate the sunk costs of entry.
} 
variable.

Importantly, the model allows for both positive and negative effects of competitors on profits. This flexibility is crucial because the literature on export spillovers allows for positive interactions between firms in their export market decisions; see inter alia Aitken et al. (1997), Koenig et al. (2010) and Choquette \& Meinen (2015). The idea is that firms may benefit from the export experience of their peers, e.g., due to informational spillovers, network effects, external scale economies in serving export markets, or other positive externalities. On the other hand, standard models of oligopolistic markets would predict negative effects of competitor entry on profits. This will be the case if competition between Danish producers is fierce, and the presence of other Danish competitors on the export market therefore reduces sales and profits. Whether the net effect of these opposing forces is positive or negative is an empirical question, and will determine the sign of the competitive effects $\delta_{1}, \delta_{l}$, and $\delta_{h}$.

From here on, $\boldsymbol{\theta}$ denotes the vector of the parameters to be estimated.

In each market, a firm decides to export its variety $i$ as long as $\pi_{i m} \geq 0$. This leads to a set of inequality conditions for all potential entrants within a market, where each firm's decision affects its competitors' decision via the competitive effects $\delta_{1}, \delta_{l}$, and $\delta_{h}$. In each market, we therefore have a system of $K_{m}$ simultaneous inequalities (recall that $K_{m}$ is the number of potential entrants in the market).

We use the pure strategy Nash Equilibrium solution concept to solve this entry game. A set of export decisions is an equilibrium outcome of the game if no individual firm can improve her pay-off by individually changing her action, taking the actions of all other potential entrants into account.

In their path-breaking contribution, Bresnahan \& Reiss (1990) show that with more than two firms one must assume away any heterogeneity across firms in the effect of observable determinants of profits in order to have a model with a unique equilibrium in the number of firms. However, in three-player games, for example, where one firm is large and the other two firms are small, there can be multiple equilibria where one equilibrium includes the large firm as a monopolist while the other equilibrium has the smaller two firms as duopolists. In our analysis, one of the competitor-and-market specific variables affects the competitive effects across firms (through the parameter $\delta_{l}$ ), which, in turn, may lead to the existence 
of multiple equilibria. Ciliberto \& Tamer (2009) provide a methodology that allows general forms of heterogeneity in the effect of the observable determinants of profits.

\section{$2.1 \quad$ Identification}

We now briefly discuss the identification and estimation methodology, and refer to Ciliberto \& Tamer (2009) for a more detailed and comprehensive presentation.

The fundamental identification problem that we face is the one that Manski (1993) called the "reflection" problem. Firms might be exporting to the same destination because of exogenous (contextual) effects, for example, because a market is particularly attractive. Firms may export because of correlated effects, such as common supply or demand shocks (unobservable to the econometrician), so that firms' export decisions may be correlated even absent any interdependence in export decisions. Finally, the export decision is also determined by the strategic interaction between the firms (endogenous effects). One crucial concern is that if industry- or market-specific unobserved common shocks affect all potential competitors in a market and are not accounted for, we might find a spuriously positive sign for the competitive effects, $\delta_{1}, \delta_{l}$, and $\delta_{h}$.

Our equilibrium approach permits us to identify the competitive effects because we model the strategic interaction through a classical simultaneous equation system. To begin with, the exogenous variables in $\mathbf{X}_{m}$ and $\mathbf{Z}_{i m}$ control for the exogenous observable factors that make exporting into a specific market particularly attractive. We also exploit exogenous variation across markets in the number of potential entrants, $K_{m}$. In particular, when there is only one potential firm in the market, the model reduces to the probit case, and the parameters of the exogenous variables can be point identified. As in Ciliberto \& Tamer (2009), we maintain that we have a random sample of observations $\left(\mathbf{y}_{m}, \mathbf{X}_{m}, \mathbf{Z}_{m}\right), m=1 \ldots N_{m}$, and $N_{m} \rightarrow \infty$.

To identify the competitive effects we use instrumental variables that affect the decision of one firm to export to a market, without affecting the decision of its competitors. As in Ciliberto \& Tamer (2009), exclusion restrictions play an important role in identification. In our specification of the profit function, the vector of competitor characteristics $\mathbf{Z}_{i m}$ enters only variety $i$ 's profit and thus fulfills the exclusion restriction. These variables shift the 
return to export of variety $i$ without shifting the returns to export of its competitors. In our main specification, one of the variables in $\mathbf{Z}_{i m}$ is also allowed to affect the profits of other firms directly (via the parameter $\delta_{l}$ ). In that case the variable is not considered an instrumental variable in the estimation.

Finally, we maintain that the random vector $\epsilon$ is continuously distributed on $R^{K}$ independently of $X=\left(X_{1}, \ldots X_{K}\right)$ and has a joint distribution function $F$ that is known to the econometrician. More specifically, we model $\epsilon_{i m}$ as the sum of four components:

$$
\epsilon_{i m}=\eta_{i}+\eta_{m}+\eta_{I}+\eta_{i m}
$$

First, we allow for random demand or supply shocks that are common across markets for a given variety, here denoted by $\eta_{i}$. Second, we include random shocks to profitability that are common for all competitors in a given market, here denoted by $\eta_{m}$ (where $m$ is a combination of an industry $I$ and a destination $c$ ). Next, we include a component that is common across markets and varieties for a given industry, $\eta_{I}$. Finally, there is an idiosyncratic component $\eta_{i m}$. All components are assumed to be drawn from standard normal distributions, and therefore we do not estimate the variance-covariance matrix.

\subsection{Estimation}

The estimation methodology consists of three steps.

We begin by estimating the empirical probability of observing the market structures conditional on the exogenous characteristics (including the number of potential entrants). To estimate the conditional choice probability vector $P(\mathbf{y} \mid \mathbf{K}, \mathbf{X}, \mathbf{Z})$, we use a nonparametric conditional expectation frequency estimator that counts the fraction of times an outcome (a market structure) is observed among all the market observations with that number of potential entrants and with those exogenous characteristics.

Next, we derive the predicted choice probabilities of the market structures for the values of the exogenous variables and different parameter values. Because of the possibility of multiple equilibria, and because we do not want to introduce arbitrary equilibrium selection assumptions, we follow Ciliberto \& Tamer (2009), and derive the following upper and lower 
bounds on conditional choice probabilities:

$$
\begin{aligned}
\mathbf{H}_{1}(\theta, \mathbf{X}, \mathbf{Z}) & \equiv\left[\begin{array}{c}
H_{1}^{1}(\theta, X, Z) \\
\vdots \\
H_{1}^{2^{K m}}(\theta, X, Z)
\end{array}\right] \leq\left[\begin{array}{c}
\operatorname{Pr}\left(\mathbf{y}_{1} \mid X, Z\right) \\
\vdots \\
\operatorname{Pr}\left(\mathbf{y}_{2_{m}^{K}} \mid X, Z\right)
\end{array}\right] \leq\left[\begin{array}{c}
H_{2}^{1}(\theta, X, Z) \\
\vdots \\
H_{2}^{2^{K_{m}}}(\theta, X, Z)
\end{array}\right] \\
& \equiv \mathbf{H}_{2}(\theta, \mathbf{X}, \mathbf{Z})
\end{aligned}
$$

where $\operatorname{Pr}(\mathbf{y} \mid X, Z)$ is a $2^{K_{m}}$ vector of conditional choice probabilities. The inequalities are interpreted element by element.

The H's are functions of $\boldsymbol{\theta}$, the set of all the parameters to be estimated. ${ }^{6}$ The lower bound function $\mathbf{H}_{1}$ is the probability that a particular market structure is the unique equilibrium. The upper bound function $\mathbf{H}_{2}$ is the probability that a market structure is a unique equilibrium or one of the multiple equilibria. We further discuss the lower and upper bounds in Appendix A.3.

As Tamer (2003) and Ciliberto and Tamer(2003) discuss in detail, this is a conditional moment inequality model, whose identified feature is the set $\Theta$ of parameter values that obey these restrictions for all $\mathbf{X}, \mathbf{Z}$, almost everywhere. In general, the set $\Theta$ is not a singleton.

Finally, the third step consists of minimizing an appropriately defined distance function constructed from the differences between the probabilities of market structures observed in the data, and the lower and upper probabilities predicted by the equilibrium model. Our inferential procedures uses the following objective function:

$$
Q(\theta)=\int\left[\left\|\left(P(\mathbf{X})-H_{1}(\mathbf{X}, \theta)\right)_{-}\right\|+\left\|\left(P(\mathbf{X})-H_{2}(\mathbf{X}, \theta)\right)_{+}\right\|\right] d F_{x}
$$

where $(A)_{-}=\left[a_{1} 1\left[a_{1} \leq 0\right], \ldots, a_{2^{k}} 1\left[a_{2^{K}} \leq 0\right]\right]$ and similarly for $(A)_{+}$for a $2^{k}$ vector $A$ and where $\|$.$\| is the Euclidian norm. Ciliberto \& Tamer (2009) show that Q(\theta) \geq \mathbf{0}$ for all $\theta \in \Theta$ and that $Q(\theta)=\mathbf{0}$ if and only if $\theta \in \Theta$.

The estimation is implemented with a simulation approach as in Ciliberto \& Tamer

\footnotetext{
${ }^{6}$ They are also functions of the distribution functions $F$ of the random vector $\epsilon$, here assumed to be the combination of four standard normal distributions, cf. above.
} 
(2009), to which we refer the reader for the detailed description. Computational details are provided in Appendix A.3.

\section{$3 \quad$ Data and Stylized Facts}

\subsection{Description of Data Set}

Our starting point is a data set from Denmark on the universe of export transactions. We observe the products each firm is exporting, and to which destinations it is serving these products. Products are classified according to the eight-digit level of the Combined Nomenclature $(\mathrm{CN})$.

Our empirical analysis focuses on industries rather than products, because we want to account for competition across different product codes that are close substitutes. For each firm and destination, we aggregate product-level export information up to the industry-level using a correspondence table between eight-digit CN codes and four-digit NACE industry codes. The product-level data might not capture the relevant competitive effects. For example, within the "Chocolate and confectionery industry", there are different eight-digit product codes for "chocolate, not filled", "chocolate, filled", or "white chocolate". Arguably, producers within this industry are competing with each other even if they are completely specialized in different eight-digit products.

Using a unique firm identifier, we also combine the export data with firm-level balance sheet information including firm revenue. We focus on a cross-section for the year 2007, for which we have information on tariffs.

Our estimation sample includes superstar exporters, defined as firms with a share in industry-level exports of at least five percent. ${ }^{7}$ For each industry, the remaining firms are bundled into a "competitive fringe". For most of the analysis, we assume that these fringe firms do not affect the market outcome, defined as the behavior of the superstar firms. This assumption is motivated by previous research arguing that small producers do not compete

\footnotetext{
${ }^{7}$ Note that industry membership is not based on the balance sheet information (which typically assigns firms to their "core" activity) but on the export data; firms may therefore be active in more than one industry. We record at least one superstar in each four-digit manufacturing industry.
} 
directly with large producers, e.g., because they produce niche products (Audretsch et al., 1999; Holmes \& Stevens, 2014). ${ }^{8}$

We restrict the sample in several dimension in order to focus on the issue at hand. First, we only consider manufacturing firms. We apply this restriction because wholesalers, retailers, and other trade intermediaries may behave fundamentally different from manufacturers (see Bernard et al. (2015) for empirical evidence). Second, we want to focus on destinations where exporting is in principle attractive for Danish firms. We therefore only keep the top 100 destinations (as measured by the number of entrants across all industries) and only markets where we see positive exports of firms in our sample for at least two years over the period 2003-2007. Our final sample accounts for 72 percent of overall Danish manufacturing exports. ${ }^{9}$

After keeping only destinations for which key variables (GDP and distance) are available, we are left with 98 destinations, 206 industries, and 8,938 markets. Hence, our sample restrictions regarding export attractiveness leave us with 43 destinations per industry, on average. The majority of markets (88 percent) are served by at least one Danish superstar firm, while less than half (48 percent) are served by two firms or more.

\subsection{Export Superstars and Export Concentration}

Figure 1 highlights the concentration of exports among a few superstars for our sample of Danish manufacturing firms. Among all firms (including the competitive fringe), the top 1 percent of exporters account for 47 percent of overall manufacturing exports, while the top 10 percent account for 85 percent (see Figure 1(a)). While this level of concentration is somewhat lower than for example in the United States (Bernard et al., 2007), it is comparable to other European countries (see World Trade Organization, 2008).

Next, we turn to the industry level. Figure 1(b) shows that the top firms again account for the bulk of exports: on average, the largest exporter covers approximately 45 percent of industry-level exports. The top 5 exporters together have a cumulative share of 80 percent in the average industry. However, the second largest firm is typically less than half as big

\footnotetext{
${ }^{8}$ Appendix B examines the robustness of our results to accounting for competition from the competitive fringe.

${ }^{9}$ We perform a number of robustness checks regarding the construction of the sample; see Appendix B.
} 
Figure 1: Export Concentration in Danish Manufacturing

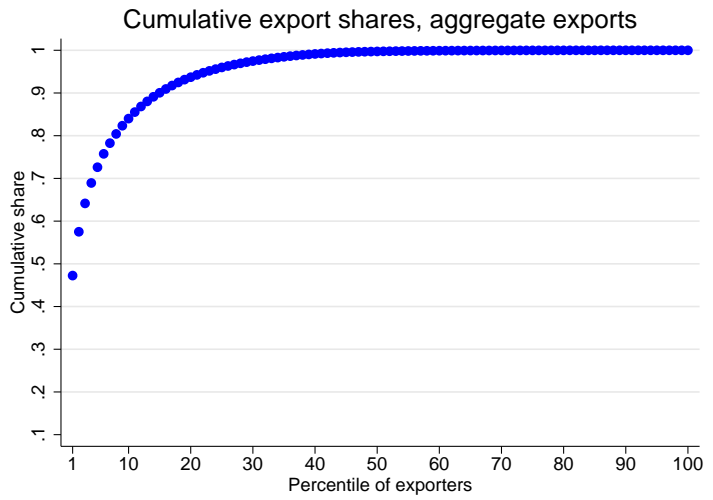

(a) Cumulative Shares for Aggregate Exports

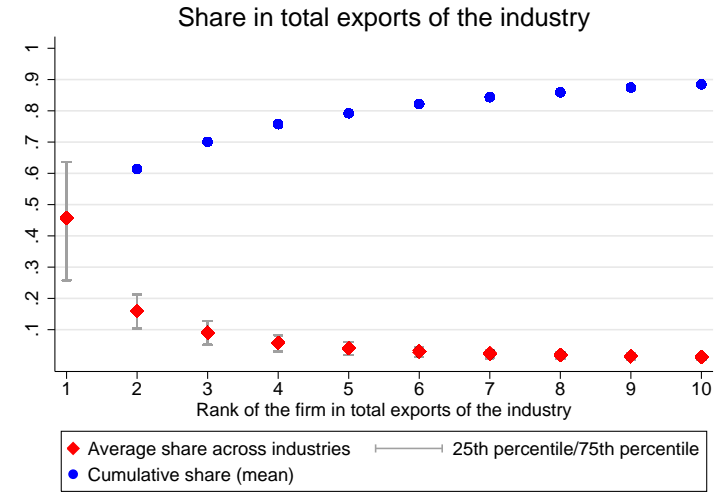

(b) Export Concentration by Industry

as the top firm in terms of exports. Together with Figure 1(a), these numbers imply that exploring the behavior of superstar exporters is crucial for understanding aggregate export patterns.

Table 1 shows that export superstars are distinctly different from the mass of fringe firms. The top panel classifies firms as superstars if the firm is a superstar in at least one of the industries in which it is active. It highlights that superstar firms are superior to fringe firms in many dimensions, including size, productivity, and export persistence. On average, superstar firms are active in 16 industries compared to 5 for fringe firms, though they are typically classified as superstars only in their core industry.

The lower panel of Table 1 compares key firm-industry-specific variables for superstar and fringe varieties. ${ }^{10}$ Superstar varieties have on average a share in overall industry-wide exports of 20 percent (compared to 0.2 percent for fringe varieties). Moreover, superstar varieties are active on significantly more export markets: the median superstar variety is exported to 16 destinations, while the median fringe variety is only sold in one destination. Again, we also find that superstar varieties have a significantly higher persistence in export status.

In the remaining analysis, our focus will be on superstar varieties.

\footnotetext{
${ }^{10} \mathrm{~A}$ firm may be a superstar only in a subset of the industries in which it is active; i.e., a firm might have both superstar and fringe varieties.
} 


\subsection{Observed Market Structures}

We are interested in the market-specific export choices of superstars, defined by a dummy variable $y_{i m}$ equal to one if variety $i$ records positive exports in market $m$, where a market was defined in Section 2 as a combination of an industry $I$ and a destination $c$. The outcome of interest is the equilibrium market structure, given by the vector of export decisions of all potential entrants in a market. Recall that the set of potential entrants for a given market $m\left(K_{m}\right)$ is defined as the set of Danish superstars with exports in industry $I$ to at least one of the 98 destinations in the sample.

Table 2 summarizes the observed market structures in our sample, separately for markets with different numbers of potential entrants $K_{m}$. For example, there are 1,095 markets with two potential entrants. In around half of these markets (48 percent), we see only one of the two superstar firms exporting. In 38 percent of the markets, both firms export, whereas a small share of markets (14 percent) is not served by any of the two firms. Note that there are also 505 markets with only one potential entrant. As explained in Section 2, these markets do not contribute to the estimation of the competitive effects, but help identify the other parameters of the profit function.

In the last line of Table 2, we also report the market structures for all 8,938 markets (i.e.,

Table 1: Export Superstars vs. Fringe Firms/Varieties

\begin{tabular}{|c|c|c|c|c|c|c|}
\hline & \multicolumn{3}{|c|}{ Superstar Firms } & \multicolumn{3}{|c|}{ Fringe Firms } \\
\hline & Mean & Median & $\mathrm{N}$ & Mean & Median & $\mathrm{N}$ \\
\hline Number of employees & 285.0 & 104 & 595 & 34.53 & 14 & 3,766 \\
\hline Log labor productivity & 13.23 & 13.19 & 585 & 13.09 & 13.09 & 3,375 \\
\hline Lagged export status & 0.988 & 1 & 595 & 0.861 & 1 & 3,766 \\
\hline \multirow[t]{3}{*}{ Number of industries } & 16.04 & 12 & 595 & 5.145 & 3 & 3,766 \\
\hline & \multicolumn{3}{|c|}{ Superstar Varieties } & \multicolumn{3}{|c|}{ Fringe Varieties } \\
\hline & Mean & Median & $\mathrm{N}$ & Mean & Median & $\mathrm{N}$ \\
\hline Share in total industry exports & 0.203 & 0.123 & 798 & 0.002 & 0.000 & 26,295 \\
\hline Lagged export status & 0.939 & 1 & 798 & 0.547 & 1 & 26,295 \\
\hline Number of destinations & 22.45 & 16 & 798 & 3.411 & 1 & 26,295 \\
\hline Rank within firm portfolio & 2.203 & 1 & 798 & 9.254 & 6 & 26,295 \\
\hline Core industry dummy & 0.643 & 1 & 798 & 0.139 & 0 & 26,295 \\
\hline
\end{tabular}

Notes: Superstar firms are defined as firms which have a share in industry-wide exports of 5 percent for at least one industry in which they are active. Superstar varieties are firm-industry combinations with a share in industry-wide exports of at least 5 percent. 
Table 2: Market Structures

\begin{tabular}{|c|c|c|c|c|c|c|c|c|c|c|}
\hline \multirow[b]{2}{*}{$\begin{array}{l}\text { Number of } \\
\text { potential entrants } \\
K_{m}\end{array}$} & \multicolumn{8}{|c|}{ Number of actual entrants } & \multicolumn{2}{|l|}{ Total } \\
\hline & $\begin{array}{l}0 \\
\%\end{array}$ & $\begin{array}{l}1 \\
\%\end{array}$ & $\begin{array}{l}2 \\
\%\end{array}$ & $\begin{array}{l}3 \\
\%\end{array}$ & $\begin{array}{l}4 \\
\%\end{array}$ & $\begin{array}{l}5 \\
\%\end{array}$ & $\begin{array}{l}6 \\
\%\end{array}$ & $\begin{array}{l}7 \\
\%\end{array}$ & No. & $\%$ \\
\hline 1 & 16.24 & 83.76 & & & & & & & 505 & 5.65 \\
\hline 2 & 13.79 & 48.04 & 38.17 & & & & & & 1,095 & 12.25 \\
\hline 3 & 11.12 & 46.68 & 25.29 & 16.91 & & & & & 1,538 & 17.21 \\
\hline 4 & 11.18 & 38.86 & 26.52 & 15.43 & 7.99 & & & & 2,164 & 24.21 \\
\hline 5 & 9.97 & 35.59 & 22.14 & 13.31 & 12.17 & 6.82 & & & 1,495 & 16.73 \\
\hline 6 & 11.23 & 28.23 & 17.9 & 14.97 & 12.04 & 10.09 & 5.53 & & 1,229 & 13.75 \\
\hline 7 & 10.96 & 24.45 & 18.75 & 12.94 & 9.32 & 9.87 & 8.33 & 5.37 & 912 & 10.20 \\
\hline Total & 11.56 & 40.39 & 23.53 & 12.25 & 6.58 & 3.54 & 1.61 & 0.55 & 8,938 & 100 \\
\hline
\end{tabular}

Notes: the number of potential entrants is given by the number of superstar varieties with a share in total industry exports of more than 5 percent. Each cell reports the percentage of markets (industry-destination combinations) for which we observe a given number of actual entrants.

independent on the number of potential entrants). The most common market structure, accounting for 40 percent of markets, is one where we only see a single superstar firm exporting. We observe two exporters in 24 percent of the markets, and three exporters in 12 percent of the markets. Very few markets have four or more exporters.

The maximum number of potential entrants in our sample is seven, while the median is four. With up to seven potential entrants, there are up to $2^{7}=128$ different market structures that we must account for.

Importantly, the observed market structures in Table 2 may be perfectly in line with a standard model of firm heterogeneity without any strategic interactions, such as Melitz (2003). Melitz (2003) predicts that only the "best" firm (i.e., the top competitor) within an industry might enter the most difficult destinations; and thus even in the standard model we would expect to see a lot of markets with only one entrant. We now provide some preliminary evidence that it is not always the case that only the top competitor enters the most difficult markets.

Figure 2 shows the market structures by destination, looking only at the top 2 Danish exporters in an industry. More specifically, we rank firms by their share in total industrywide exports and focus on the top 2 competitors (which we refer to as Firm 1 and Firm 2). On the horizontal axis, the destinations are ranked by their popularity, which is measured by the number of actual entrants across all industries. On the vertical axis, we plot the frequency of market structures in that destination, where we distinguish between markets where $(i)$ only Firm 1 enters, (ii) only Firm 2 enters, and (iii) both Firm 1 and Firm 2 
Figure 2: Market Structures for Top 2 Firms

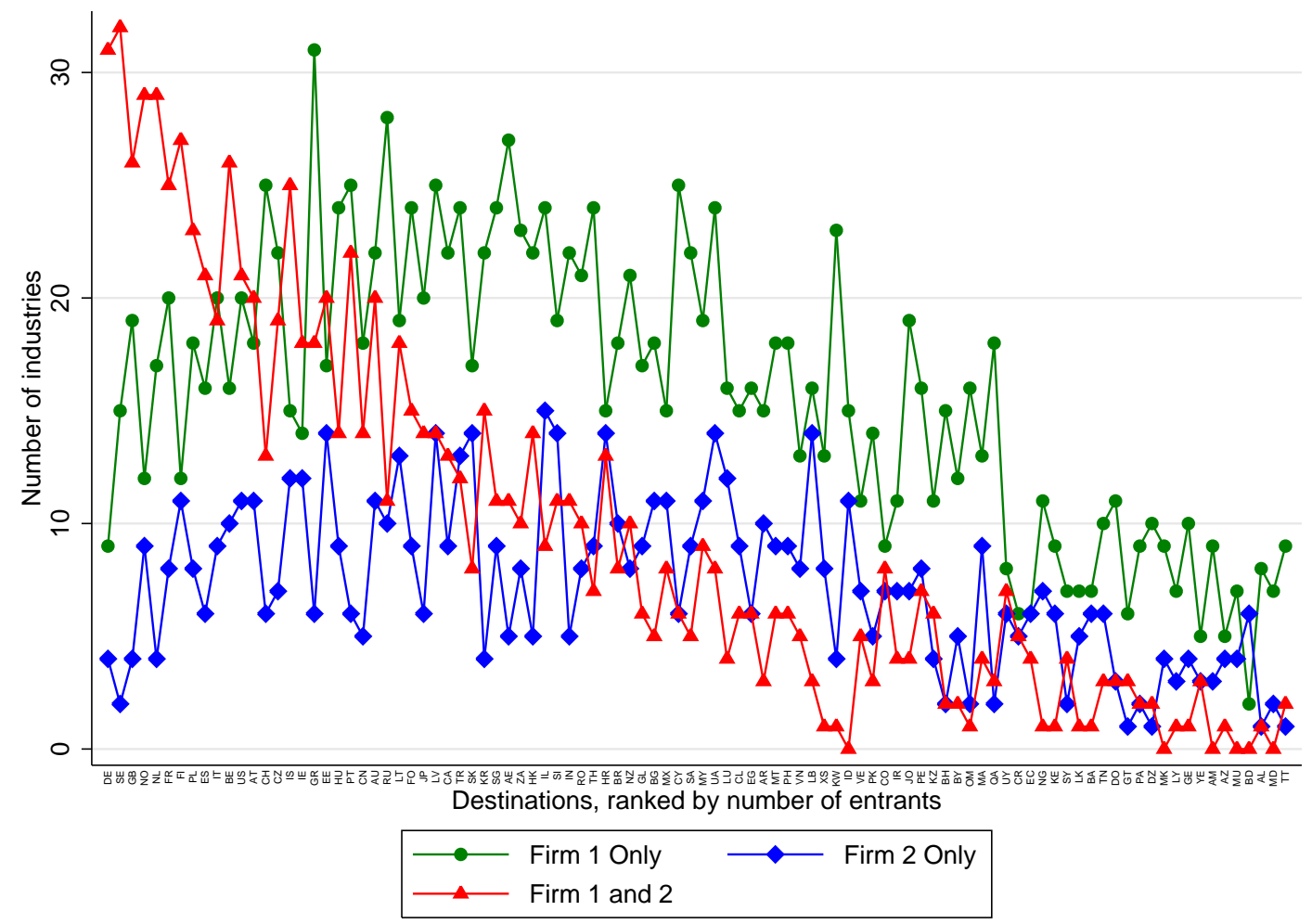

enter. $^{11}$

As expected, it is more likely that the top 2 competitors both enter in the most popular destinations, such as Germany, Sweden, and Great Britain. Moreover, the number of industries in which we see both firms exporting sharply declines in the more difficult destinations.

Since Firm 1 is the top competitor, it should be more likely that Firm 1 is the sole exporters in a given destination; and this is indeed reflected in Figure 2. However, the figure also shows that there are many instances where Firm 2 exports to a destination and Firm 1 does not. This pattern in the data is at odds with a standard model of firm heterogeneity, where any market served by Firm 2 should also be served by Firm 1. We will argue that the existence of markets where only Firm 2 exports can (partly) be explained by the strategic interaction between firms, where the presence of Firm 2 preempts entry of Firm 1. ${ }^{12}$

\footnotetext{
${ }^{11}$ We exclude markets with no entrants and markets where other firms beside the top 2 enter. We also exclude industries with only one potential entrant.

${ }^{12}$ The pattern seen in Figure 2 is also related to the finding in the empirical trade literature that there is no strict hierarchy of export destinations (in the sense that any firm exporting to the $\ell+1$-th most popular market also exports to the $\ell$-th most popular market); see Lawless (2009) and Eaton et al. (2011). Eaton et al. (2011) explain this pattern with random firm-and-market specific entry shocks. Note that our empirical model laid out in Section 2 explicitly allows for such random shocks to profitability as well.
} 


\subsection{Variable Definitions}

Table 3 summarizes the exogenous variables governing the profit function. Many of these variables are included in logs in the empirical model (see below), but to ease interpretation we report summary statistics for variables in levels here.

\section{Competitor-Specific Variables}

First, we discuss the variables included in the vector $\mathbf{Z}_{i m}$.

We count the number of industries where a firm is an exporter, and we call this variable Firm Industries. We also rank the firm's varieties (i.e., the industries in which the firm

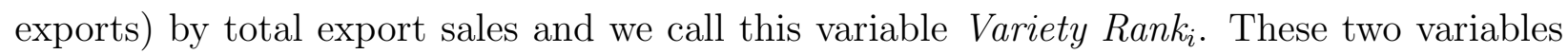
vary only across competitors. They are inspired by the literature on multi-product firms, which emphasizes economies of scope in exporting multiple products; see inter alia Eckel \& Neary (2010), Bernard et al. (2011) and Mayer et al. (2014). Thus, we would expect firms which are active in more industries, and thus have a higher value of Firm Industries ${ }_{i}$, to be more likely to serve a given market. Moreover, the literature predicts that multi-product firms are more likely to export their core product to a given market, and that the probability of exporting decreases as we move away from the firm's core competency. This is captured by the variable Variety Rank, which is expected to be negatively correlated with export decisions.

Next, for each variety and destination, we count the number of other destinations to which the variety is exported and call this variable Variety Destinations $s_{i m}$. The idea here is that varieties are more likely to be exported to a given market the more successful they are on other markets: for example, firms may learn about their export profitability from exporting to other destinations (see Albornoz et al. (2012), Morales et al. (2017)); demand may be correlated across markets (see e.g. Nguyen (2012)); and - more in general - being successful on other markets may be a sign that the variety offers characteristics highly demanded by consumers. ${ }^{13}$

\footnotetext{
${ }^{13}$ The correlation of export profitability across markets may crucially depend on how similar markets are in terms of income per capita, culture and other characteristics; see e.g. Morales et al. (2017). We leave this kind of analysis to future work.
} 
Table 3: Summary Statistics

\begin{tabular}{|c|c|c|c|}
\hline & Mean & Std dev & $\overline{N N}$ \\
\hline \multicolumn{4}{|c|}{ Competitor-specific variables $\mathbf{Z}_{i m}$} \\
\hline Firm Industries $_{i}$ & 23.31 & 20.03 & 37,198 \\
\hline 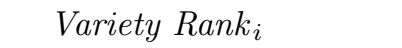 & 1.729 & 1.933 & 37,198 \\
\hline Variety Destinations $s_{i m}$ & 30.07 & 24.09 & 37,198 \\
\hline \multicolumn{4}{|l|}{ Market-specific variables $\mathbf{X}_{m}$} \\
\hline$G D P_{c}$ & 858.0 & 2,011 & 37,198 \\
\hline Geographical Distance $_{c}$ & 4.066 & 3.968 & 37,198 \\
\hline${\text { Industry } \text { Size }_{I}}$ & 91,653 & 68,515 & 37,198 \\
\hline$H H I_{m}$ & 0.191 & 0.137 & 36,650 \\
\hline Tariffs $s_{m}$ & 0.0400 & 0.147 & 36,037 \\
\hline Tariff $_{m}>0$ & 0.424 & 0.494 & 36,037 \\
\hline
\end{tabular}

\section{Market-Specific Variables}

Next, we review the variables which are included in the vector $\mathbf{X}_{m}$. Recall that $m$ is a combination of an industry $I$ and a destination $c$.

We use information on GDP from the World Development Indicators (WDI) and geographical distance from the CEPII's GeoDist database to measure market size and transportation costs. We denote these variables $G D P_{c}$ and Distance $_{c}$.

Next, for each industry, we construct a measure of industry size as the total revenue at manufacturing firms with positive exports in this industry. We call this variable Industry Size $_{I}$. We include this variable to control for differences across industries in the role of the competitive fringe. To understand this modeling choice, consider the ideal framework where there is a dominant set of firms (the superstars) and a fringe of competitive firms. In such a model, competitive firms will enter if the superstars do not cover all of the market demand, which would happen if the competitive fringe has lower costs, or if the market size (total demand) is large. Since the former is not likely to be the case, we maintain that the industry size proxies for the role of the competitive fringe.

In some of our specifications, we also include the market-specific Herfindahl-Hirschman index, which we call $H H I_{m}$. To construct this variable, we use information on trade by product, exporter, and importer from the BACI database of the CEPII. We aggregate this information up to the industry-country-pair level in order to match the market definition in our empirical model. $H H I_{m}$ is then defined as the sum of squared import shares across all 
Figure 3: Distribution of Tariffs

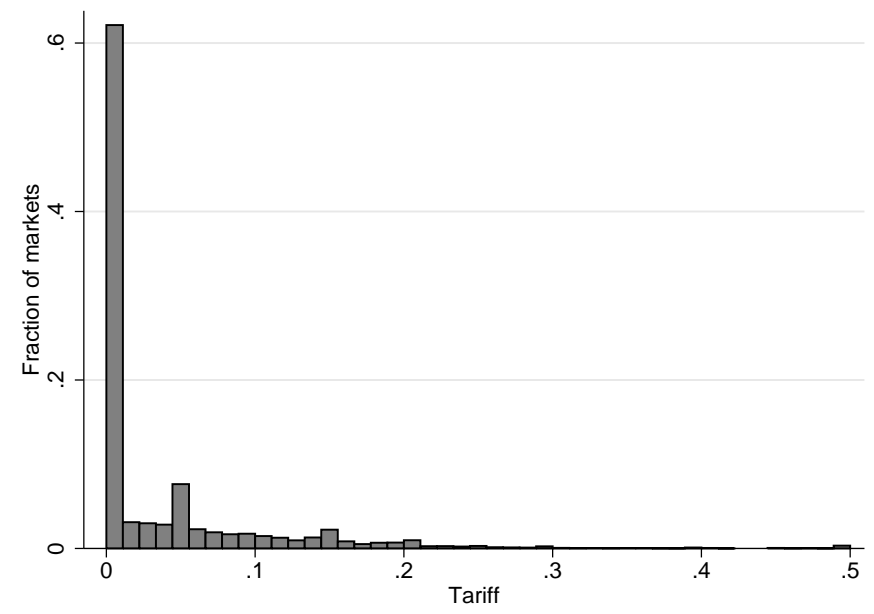

Note: Tariffs are capped at 50 percent.

import origins. A higher value of $H H I_{m}$ implies that the import market is more concentrated. We use this variable to control for competition from non-Danish competitors. ${ }^{14}$

\section{Tariffs}

We employ data on applied, preferential tariff protection in 2007 from the third version of the MAcMap-HS6 database (Guimbard et al., 2012) to construct the variable Tariff ${ }_{m}{ }^{15}$ We aggregate product-level tariffs up to the industry level, weighting products by their importance for overall Danish exports. The average tariff across markets in our sample is 4 percent (see Table 3). However, Figure 3 shows that exports are duty-free in the majority of markets. Thus, we also construct an indicator variable Tariff $_{m}>0$ equal to one for markets with positive tariffs, and zero otherwise.

\section{Standardization and Discretization of Variables}

In the following, all variables (except for indicator variables) are standardized. When we estimate the equilibrium model in Section 5, we furthermore discretize all variables. The discretization is described in detail in Appendix A. In the case of the variable Tariff $f_{m}$, the very long tail of the distribution (see Figure 3) would leave us with few observations in each

\footnotetext{
${ }^{14}$ Note that there are slightly fewer observations for this variable because a few products that appear in the Danish data are not included in the BACI database.

${ }^{15}$ We thank Houssein Guimbard for giving us access to these data.
} 
bin. Thus, in the equilibrium model we employ the indicator variable Tariff $_{m}>0$.

Note that all control variables in Table 3 (except for indicator variables and the HHI) are included in logs in the empirical model.

\section{Results from a Single Equation Probit Model}

In this section, we estimate a model where firms make their export decisions independently of each other. Thus, the model in Equation (1) reduces to a (standard) single equation probit model, where the unit of analysis is the firm-industry-destination (and not the market). We focus on the estimation of the constant competitive effect $\delta_{1}$ here, and leave the estimation of the heterogeneity in the competitive effects - as captured by $\delta_{l}$ and $\delta_{h}$ in Equation (1)to the equilibrium model. ${ }^{16}$

Table 4 reports the parameter estimates and standard errors for different specifications with and without market random effects and with different sets of control variables. Table 5 reports marginal effects based on columns (3) to (5) of Table 4 . In order to ensure comparability with the marginal effects in the equilibrium model in Section 5, we calculate the marginal effect of each variable as the change in predicted probability when the variable is increased by one unit. ${ }^{17}$ Since all control variables (except for indicator variables) are standardized, the marginal effects thus correspond to the effects of increasing each variable by one standard deviation.

Column (1) of Table 4 includes a set of basic controls but does not account for unobserved market heterogeneity. The main parameter of interest is the constant competitive effect $\left(\delta_{1}\right)$, which is the coefficient on the count of the number of competitors active in market $m$. The estimate for the competitive effect is positive and significant. Thus, the presence of a competitor in a market is predicted to increase the export probability, which supports the spillover hypothesis. Note, however, that this specification does not control for marketspecific random shocks to profitability, $\eta_{m}$. In fact, a positive shock $\eta_{m}$ may increase the export probability of all firms. The positive estimate of $\delta_{1}$ in column (1) may thus be

\footnotetext{
${ }^{16}$ The single equation model does, in fact, not allow us to estimate $\delta_{l}$, the heterogeneity across competitors in the competitive effect.

${ }^{17}$ In the econometrics literature, this method of calculating marginal effects is referred to as the "finitedifference method".
} 
Table 4: Parameter Estimates from the Simple Probit Model

\begin{tabular}{|c|c|c|c|c|c|}
\hline & \multicolumn{5}{|c|}{ Dependent Variable: Variety Export Status, by Market } \\
\hline & $(1)$ & $(2)$ & $(3)$ & (4) & $(5)$ \\
\hline \multirow{2}{*}{ Competitive Effect $\left(\delta_{1}\right)$} & $0.068^{* * *}$ & $-0.510^{* * *}$ & $-0.519^{* * *}$ & $-0.538^{* * *}$ & $-0.544^{* * *}$ \\
\hline & $(0.006)$ & $(0.011)$ & $(0.011)$ & $(0.011)$ & $(0.011)$ \\
\hline \multirow[t]{2}{*}{ Firm Industries $i$} & $0.037^{* * *}$ & $0.052^{* * *}$ & $0.043^{* * *}$ & $0.034^{* * *}$ & $0.036^{* * *}$ \\
\hline & $(0.010)$ & $(0.013)$ & $(0.013)$ & $(0.013)$ & $(0.013)$ \\
\hline \multirow[t]{2}{*}{ Variety $\operatorname{Rank}_{i}$} & $0.022^{* *}$ & $-0.022^{*}$ & -0.018 & -0.017 & -0.016 \\
\hline & $(0.009)$ & $(0.012)$ & $(0.012)$ & $(0.012)$ & $(0.012)$ \\
\hline \multirow[t]{2}{*}{ Variety Destinations $s_{i m}$} & $0.846^{* * *}$ & $1.105^{* * *}$ & $1.141^{* * *}$ & $1.179 * * *$ & $1.184^{* * *}$ \\
\hline & $(0.011)$ & $(0.014)$ & $(0.015)$ & $(0.015)$ & $(0.015)$ \\
\hline \multirow[t]{2}{*}{$G D P_{c}$} & $0.399 * * *$ & $0.728^{* * *}$ & $0.778^{* * *}$ & $0.820^{* * *}$ & $0.825^{* * *}$ \\
\hline & $(0.008)$ & $(0.015)$ & $(0.015)$ & $(0.016)$ & $(0.016)$ \\
\hline \multirow{2}{*}{ Geographical Distance $_{c}$} & $-0.439 * * *$ & $-0.791^{* * *}$ & $-0.790 * * *$ & $-0.759^{* * *}$ & $-0.598^{* * *}$ \\
\hline & $(0.008)$ & $(0.015)$ & $(0.016)$ & $(0.017)$ & $(0.021)$ \\
\hline \multirow[t]{2}{*}{ Industry Size $_{I}$} & $-0.144^{* * *}$ & -0.002 & 0.009 & -0.001 & 0.024 \\
\hline & $(0.008)$ & $(0.015)$ & $(0.015)$ & $(0.016)$ & $(0.016)$ \\
\hline \multirow[t]{2}{*}{$H H I_{m}$} & & & $-0.039 * * *$ & $-0.082^{* * *}$ & $-0.089^{* * *}$ \\
\hline & & & $(0.015)$ & $(0.015)$ & $(0.015)$ \\
\hline \multirow[t]{2}{*}{ Tariff $_{m}$} & & & & $-0.174^{* * *}$ & \\
\hline & & & & $(0.014)$ & \\
\hline \multirow[t]{2}{*}{ Tariff $_{m}>0$} & & & & & $-0.658^{* * *}$ \\
\hline & & & & & $(0.040)$ \\
\hline Number of observations & 37,198 & 37,198 & 36,650 & 36,037 & 36,037 \\
\hline Number of markets & 8,938 & 8,938 & 8,802 & 8,654 & 8,654 \\
\hline Market random effects & No & Yes & Yes & Yes & Yes \\
\hline
\end{tabular}

Notes: The table gives coefficient estimates from a probit model for the firm-industry-destination specific export status. All specifications except for column (1) include market (industry-destination) random effects. The Competitive Effect gives the count of other competitors that are active in a market. All other variables (except for Tariff $m>0$ ) are standardized. Standard errors in parentheses. ${ }^{*}, * *, * * *$ denote significance at the $10 \%, 5 \%, 1 \%$ levels, respectively.

confounded with market attractiveness.

To address this concern, column (2) adds market-level random effects $\eta_{m}$. We now find that each additional competitor in a market lowers the export probability. The negative competitive effect of column (2) is in line with standard models of strategic interaction: the presence of competitor decreases profits, and hence the probability of exporting to market $m$. The same pattern of sign reversal after accounting for market unobserved heterogeneity is found in previous studies (e.g., Ciliberto et al. (2016)).

In column (3), we additionally control for the level of concentration in the import market, as captured by the variable $H H I_{m}$. Including this measure of competition from third countries does not have a large impact on the estimated competitive effect $\delta_{1}$, which is very similar 
Table 5: Marginal Effects in the Simple Probit Model

\begin{tabular}{|c|c|c|c|}
\hline & \multicolumn{3}{|c|}{ Dependent Variable: Variety Export Status, by Market } \\
\hline & $(3)$ & $(4)$ & $(5)$ \\
\hline Competitive Effect $\delta_{1}$ & 0.1888 & 0.1914 & 0.1918 \\
\hline \multicolumn{4}{|c|}{ Competitor-specific variables $\mathbf{Z}_{i m}$} \\
\hline Firm Industries $_{i}$ & 0.0102 & 0.0079 & 0.0082 \\
\hline Variety Rank $_{i}$ & -0.0041 & -0.0038 & -0.0037 \\
\hline Variety Destinations $s_{i m}$ & 0.261 & 0.2642 & 0.2641 \\
\hline \multicolumn{4}{|l|}{ Market-specific variables $\mathbf{X}_{m}$} \\
\hline$G D P_{c}$ & 0.1825 & 0.1883 & 0.1886 \\
\hline Geographical Distance $_{c}$ & -0.1732 & -0.1639 & -0.1308 \\
\hline${\text { Industry } \text { Size }_{I}}$ & 0.0021 & -0.0003 & 0.0054 \\
\hline$H H I_{m}$ & -0.0091 & -0.0188 & -0.0204 \\
\hline Tariff $_{m}$ & & -0.0397 & \\
\hline Tariff $_{m}>0$ & & & -0.0663 \\
\hline
\end{tabular}

Notes: The table reports marginal effects for columns (3) to (5) of Table 4. The Competitive Effect gives the count of other competitors that are active in a market. All other variables (except for Tariff $_{m}>0$ ) are standardized. Marginal effects are computed as the change in predicted probability when the variable is increased by one unit.

to the estimate in column (2). Based on column (3), we predict each additional Danish competitor in a market to lower the probability of exporting by 18.8 percentage points; see Table 5. The magnitude of the effect is thus quite large, and economically meaningful because the median number of competitors faced by a firm in a given market is one. ${ }^{18}$

We expect competition to be tougher in markets with higher levels of concentration, and this should reduce the export probability of Danish firms. The estimated effect of $H H I_{m}$ in column (3) confirms this intuition. However, the corresponding marginal effect is rather small: a one standard deviation increase in $H H I_{m}$ reduces the market-specific export probability by 0.9 percentage points.

In columns (4) and (5) of Tables 4 and 5, we show that export participation is less likely in markets with higher tariffs. The tariffs are measured by the continuous variable Tariff $_{m}$ in column (4) ${ }^{19}$ and the binary variable Tariff $_{m}>0$ in column (5). We find that one standard

\footnotetext{
${ }^{18}$ There is a maximum of seven potential entrants in markets in our sample, such that the maximum number of competitors is six. Our estimates predict that the probability to export to a market where five or more competitors are active is literally zero. However, there are in fact only very few markets with more five or more entrants; see Table 2.

${ }^{19}$ Following common practice in the literature (see, e.g., Debaere \& Mostashari (2010)), tariffs are included as $\ln \left(1+\right.$ Tariff $\left._{m}\right)$. In particular, $1+$ Tariff $_{m}$ can be interpreted as the price increase on the import market which is due to the tariff.
} 
deviation increase in tariffs is predicted to decrease export participation by 3.97 percentage points. When we employ the binary tariff variable, we find that firms are 6.63 percentage points less likely to enter destination markets with positive tariffs.

Next, we briefly discuss the effects of our control variables.

Consider first our two variables that are borrowed from the literature on multi-product exporters (see, e.g., Eckel \& Neary (2010); Mayer et al. (2014); Bernard et al. (2011)). In

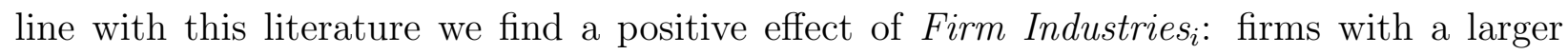
industry portfolio are more likely to serve a given export market. The effect of Variety $R a n k_{i}$ is negative in most columns that include market random effects $\eta_{m}$, but - except for column (2) - not statistically significant. Thus, we find only weak evidence that the export probability falls from the firm's core industry to its peripheral industries. However, note that we only include superstar varieties in our sample, and industries which are far away from the firms' core competency are often not included in the sample. ${ }^{20}$

A variety's presence in other destinations (Variety Destination $n_{i m}$ ) captures the general attractiveness of the variety to consumers across all destinations. Accordingly, it raises the destination-specific export probability. The corresponding marginal effect is sizable: we predict that a one standard deviation increase in Variety Destination im $_{\text {increases the }}$ export probability by 26 percentage points. This result suggests that demand and/or export profitability are correlated across markets.

Turning to the market-specific variables, varieties are more likely exported to larger and geographically closer markets, as predicted by the gravity equation. A one standard deviation increase in GDP increases the probability of firms' being present in a market by roughly 18 percent, while a one standard deviation increase in distance reduces the probability by 15 to 17 percent. The effect of industry size, Industry Size , turns out to be insignificant.

To summarize, our probit estimations suggest that negative competitive effects due to the strategic interaction between superstar exporters outweigh any positive effects from informational spillovers, i.e., the net effect is negative. Notably, this finding is quite different from previous results in the extensive literature on export spillovers. For example, based on

\footnotetext{
${ }^{20}$ In fact, summary statistics reported in Table 3 show that the average Variety Rank in our sample stands at 1.7 .
} 
Danish data, Choquette \& Meinen (2015) find that firms learn from the export experience of their competitors, and thus these authors conclude that export spillovers seem important in determining firms' export market choices. In contrast to Choquette \& Meinen (2015) and other studies, we focus on superstar firms here. It is in fact only for such a sample of large firms that we would expect oligopolistic strategic interactions to be important.

The models estimated in Table 4 do not allow for idiosyncratic shocks to profitability as in Eaton et al. (2011). However, we note that these types of shocks (denoted $\eta_{i m}$ in our notation above) would have to be negatively correlated across firms within a market in order to explain the negative estimate of the competitive effect. A more important caveat is that these single equation probit estimations do not take the market equilibrium into account. Thus, we next turn to the equilibrium model, which models the interdependence of firms' export market choices as an equilibrium outcome. Additionally, the equilibrium model also allows us to include the full set of random effects $\eta_{i}, \eta_{m}, \eta_{I}$, and $\eta_{i m}$.

\section{Results from the Equilibrium Model}

We now present the estimation results for the equilibrium model. The object of interest is either the set $\Theta$ or the (possibly partially identified) true parameter $\theta \in \Theta$. We report confidence regions for $\theta$. The confidence regions for the latter are weakly larger than for the former, and coincide asymptotically in the case of point identification. To build the confidence regions we use the methodology of Chernozhukov et al. (2007).

Column (1) of Table 6 presents estimations results for the specification with our basic control variables and only the constant competitive effect $\delta_{1}$, so that $\delta_{l}=0$ and $\delta_{h}=0$. There are three exogenous variables that are common among the potential entrants. These three

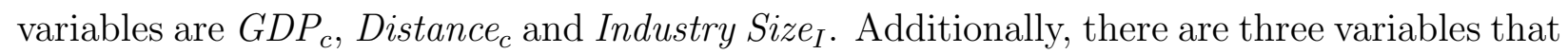
are specific to the potential entrants, and thus fulfill the exclusion restriction (cf. Section 2.1). These variables are Firm Industries , Variety Rank $_{i}$ and Variety Destinations V. $_{\text {. }}$

The parameter $\delta_{1}$ is estimated to be in [-6.707,-6.687]. Thus, the effect is negative and statistically significant as predicted in standard oligopoly models: the presence of Danish competitors in a market reduces profits, and therefore firm entry. Furthermore, any potential 
informational spillovers seem to be too small to counterbalance these negative competitive effects.

The coefficients of the variables Firm Industries ${ }_{i}$, Variety Rank Vand Variety Destinations $_{i m}$ are estimated to be in, respectively, [0.094, 0.118], [-0.098, -0.074] and [0.935, 0.956]. Hence, all estimates are statistically significant and have the same sign as in the probit model of Section 4. Interestingly, the effect of Variety Rank $k_{i}$ is not precisely estimated in the probit model, but turns statistically significant in the equilibrium model.

Next, the coefficients of the variables $G D P_{c}$ and Distance $_{c}$ are estimated to be in, respectively, [0.896,0.917] and [-0.778,-0.753]. The signs of these parameters are again consistent with the simple probit model.

We now find a positive effect of Industry Size $_{I}$, which is estimated to be in $[0.213,0.234]$. This is different from the probit regressions, where we had found statistically insignificant estimates. We interpret this as evidence that the superstar firms are more likely to export if the competitive fringe, here proxied by the variable Industry Size , $_{I}$ is larger.

Column (2) adds the market-specific Herfindahl-Hirschmann Index $H H I_{m}$. The coefficient estimate of $H H I_{m}$ is included in [-0.275,-0.259], implying that Danish superstars are less likely to enter markets where imports are more concentrated. However, the competitive effect $\delta_{1}$ only decreases slightly compared to column (1). Thus, accounting for market concentration does not significantly affect our results regarding the strategic interaction between Danish firms.

Column (3) examines the impact of tariffs on export market participation. The effect of the binary variable Tariff $_{m}>0$ is estimated to be in $[-2.732,-2.504]$, which confirms that superstars are less likely to export to markets with positive tariffs. In our policy analysis below, we will simulate the market entry response (i) if tariffs are lowered to zero in all markets with positive tariffs, and (ii) if tariffs are imposed in markets where entry is dutyfree.

Finally, Column (4) investigates whether the competitive effects vary across competitors and/or markets, i.e. we estimate the parameters $\delta_{l}$ and $\delta_{h}$ in Equation (1). Specifically, we want to test the hypothesis that dominant competitors with a broader destination portfolio have a larger negative effect on the profits of their competitors. We thus allow the competitive 


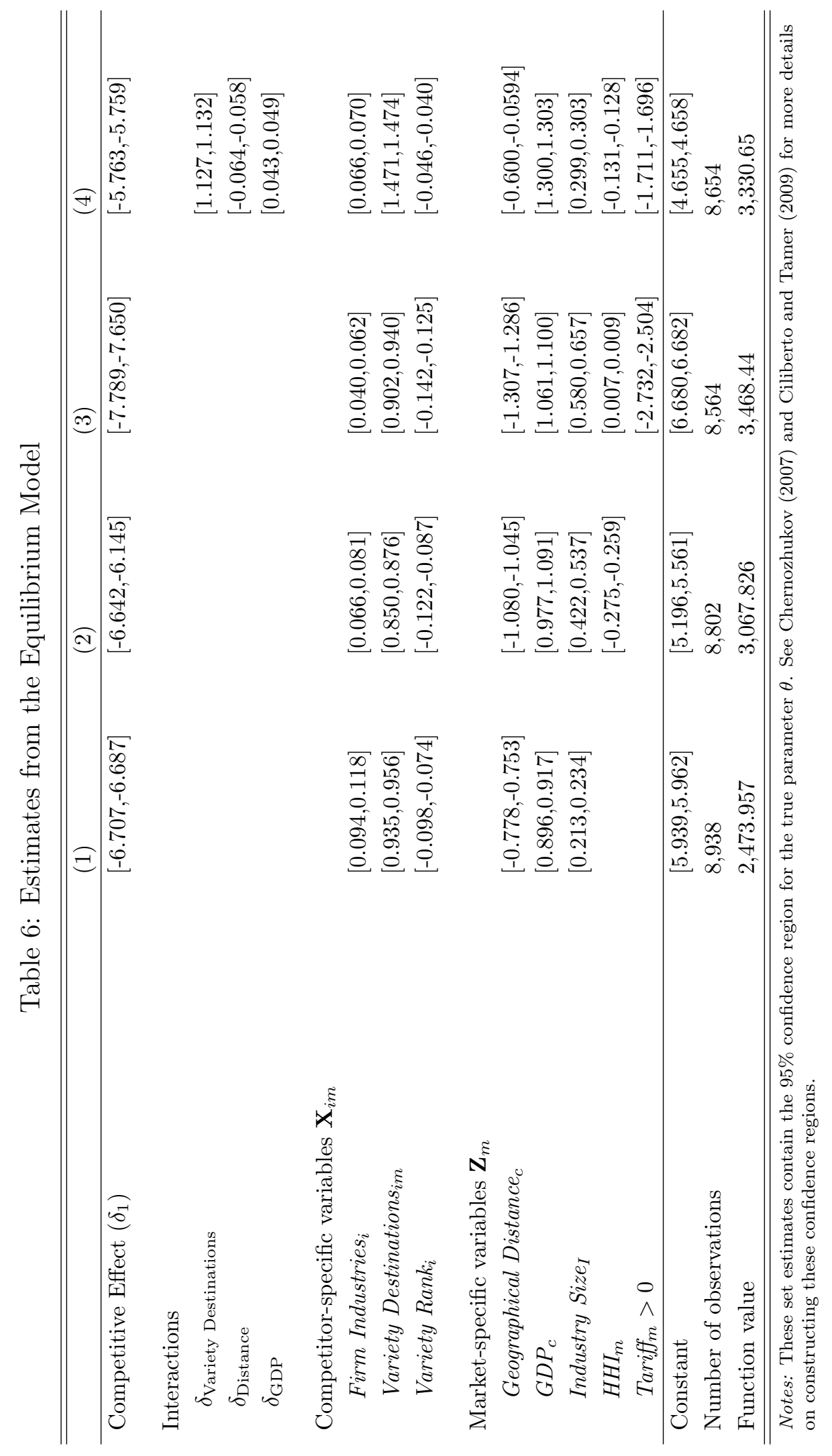


effect to change with the number of destination to which a variety is exported. This effect

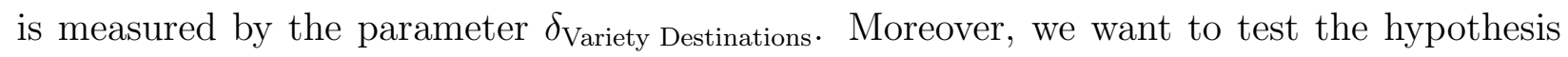
that competitive effects vary across destinations according to the standard gravity forces. We thus also allow for the competitive effects to change with the geographical distance and GDP of the destination country. These effects are measured, respectively, by $\delta_{\text {Distance }}$ and $\delta_{\mathrm{GDP}}$.

Contrary to our expectations, we find $\delta_{\text {Variety Destinations }}$ to be positive and included in $[1.127,1.132]$. Thus, the larger the number of other destinations that a firm serves, the smaller (in absolute value) its effect on competitors' profits. There are several potential interpretations for this result. First, firms that serve many export markets may have a high visibility to their competitors. This reasoning implies not only larger negative effects on profits due to strategic interactions but also a larger potential for informational spillovers. The latter may explain why we find $\delta_{\text {Variety Destinations }}>0$. Second, firms that serve a large number of other export markets may compete less aggressively in a given destination, because each destination has a lower importance for their overall exports.

Finally, we confirm that the competitive effects vary across markets depending on destination GDP and distance. We find $\delta_{\text {Distance }}$ to be in $[-0.064,-0.058]$, which implies that the overall competitive effects are larger in more distant destinations. Hence, in addition to the direct negative effects of geographical distance on export sales implied by the gravity equation, there is an additional negative effect of competitors being active in distant markets. Finally, we find $\delta_{\mathrm{GDP}}$ to be included in $[0.043,0.049]$. Thus, in larger markets, competition from other Danish competitors will have less of an impact on a firm's export decision. This is also adding to the standard gravity model, where firm sales increase with destination GDP. Intuitively, in larger markets the presence of competitors will be less detrimental for firm profits. Together, the results for $\delta_{\text {Distance }}$ and $\delta_{\mathrm{GDP}}$ suggest that negative competitive effects are larger in destination markets that are harder to enter. 


\section{$5.1 \quad$ Fit}

There are several ways to determine how well our model fits the data. First, as a measure of fit we compute the percentage of market outcomes that the model predicts correctly. Empirically, in each market we only observe one equilibrium outcome, but the model potentially predicts multiple market equilibria. In order to construct our measure of fit we therefore proceed as follows.

We draw 100 new simulations of the random shocks to profitability, $\eta_{i}, \eta_{m}, \eta_{I}$, and $\eta_{i m}$ in Equation (2), compute a new $\epsilon_{i m}$ for each firm in each market, and find the equilibria in each market at the estimated parameters in Column (4) of Table 6 and the values of the exogenous variables. Then, we check if any of the equilibria predicted by the model matches the market structure observed in the data. ${ }^{21}$ We find that our model correctly predicts 36.69 percent of the market outcomes, which is comparable to the value of 32.8 percent in Ciliberto \& Tamer (2009).

Secondly, we can compare the values of the distance function at the parameter where it is minimized across columns that use the same exogenous variables to determine the best specification. For example, the distance function is equal to 3330.65 in Column (4) and to 3468.44 in Column (3), which implies that Column (4) provides a better fit to the data. This is not surprising since the specification in Column (4) has more free parameters than the one in Column (3). Because Columns (1) and (2) are based on different sets of exogenous variables, a direct comparison of the distance functions is not meaningful.

Finally, we can compare the export propensities of firms observed in the data with those that are predicted by the model. We provide this analysis in Table 8 and discuss results in Section 6 .

\subsection{Occurrence of Multiple Equilibria}

We analyze the occurrence of multiple equilibria as follows. We use the 100 new simulations of the random shocks $\eta_{i}, \eta_{m}, \eta_{I}$, and $\eta_{i m}$ from the analysis in Section 5.1 and determine the equilibria for each market-simulation draw. We can then identify the market-simulation

\footnotetext{
${ }^{21}$ Our model may predict multiple equilibria in some of the markets. If one of the predicted equilibria matches the market structure observed in the data, then, that is a positive match.
} 
Table 7: Evidence of Multiple Equilibria in the Identity and Number of Firms

\begin{tabular}{|c|c|c|c|c|}
\hline $\begin{array}{l}\text { Number of poten- } \\
\text { tial entrants }\end{array}$ & $\begin{array}{l}\text { Number of possible } \\
\text { market structures }\end{array}$ & $\begin{array}{l}\text { Average number of } \\
\text { market equilibria }^{a}\end{array}$ & $\begin{array}{l}\text { Multiple equilibria in } \\
\text { number of firms }(\%)^{b}\end{array}$ & $\begin{array}{l}\text { Number of } \\
\text { markets }\end{array}$ \\
\hline$K_{m}=2$ & 4 & 1.45 & - & 1,058 \\
\hline$K_{m}=3$ & 8 & 2.17 & 0.03 & 1,499 \\
\hline$K_{m}=4$ & 16 & 2.99 & 0.09 & 2,093 \\
\hline$K_{m}=5$ & 32 & 3.94 & 0.11 & 1,441 \\
\hline$K_{m}=6$ & 64 & 5.09 & 0.15 & 1,196 \\
\hline$K_{m}=7$ & 128 & 6.41 & 0.15 & 884 \\
\hline Mean & - & 3.48 & 0.10 & - \\
\hline
\end{tabular}

draws with multiple equilibria, both in the identity and number of competitors. Finally, we compute the fraction of market-simulation draws with multiple equilibria.

Table 7 presents the results of this exercise. We find that in markets with two potential entrants there are on average 1.45 equilibria. Notably, these multiple equilibria are only in terms of the identity of the firms, i.e., with two firms there are markets where either of the firms being an exporter will be an equilibrium outcome. If there were informational spillovers and other positive externalities in exporting, we would also expect there to be multiple equilibria in the number of firms; i.e., equilibria where either both firms export or no firm exports. In contrast, Table 7 shows that the equilibria are always unique in the number of firms. Thus, the positive effects associated with $\delta_{\text {Variety Destinations }}$ and $\delta_{\text {GDP }}$ are not large enough to offset the negative effects of competition that are implied by $\delta_{1}$ and $\delta_{\text {Distance }}$.

Next, we look at markets with three potential entrants, and find that on average there are 2.17 equilibria (out of eight possible market structures). Moreover, in 3 percent of the simulation-market draws (here equal to $100 \times 1058)$ there are multiple equilibria in the number of firms. For example, these could be equilibria where either one large competitor or two smaller competitors export.

The results for the other configurations with more potential entrants are analogous to the case just analyzed with three potential entrants. For example, when there are seven potential entrants, on average there are 6.41 equilibria, and 15 percent of the 88,400 market- 
simulations with seven potential entrants have equilibria with different numbers of firms. Overall, in markets with at least two potential entrants, 10 percent have multiple equilibria in the number of firms, which confirms the necessity to use a flexible approach as in Ciliberto \& Tamer (2009) to study strategic interactions in export markets.

\section{Propensity to Export and Comparative Statics}

In this section we compare the propensities to export predicted by our model with the ones observed in the data and present comparative statics that focus on the individual export propensity. The comparative statistics allow us to quantify the importance of the competitive effects, and the influence of other determinants of profits. To this aim, in Table 8 export propensities are calculated (i) for the observed values of the exogenous variables and the estimated parameters, (ii) when competitive effects are 'turned off' (i.e., $\delta_{1}=\delta_{l}=\delta_{h}=0 \forall h$ ), and (iii) for a one standard deviation increase in each of the exogenous variables, holding other variables at their observed values.

Recall that the outcome of the equilibrium model is a market structure, or a vector of export decisions by multiple firms. Following Ciliberto \& Tamer (2009), marginal effects are then to be computed for the market structures, as one would do when studying the marginal effects in a multinomial logit estimation. Here, however, we focus on the response of the individual firms, and investigate how the export propensity of the individual firms changes as we change the values of the exogenous variables. Our focus on the export propensity facilitates comparison with marginal effects reported in the mainstream literature in international trade.

\subsection{Propensity to Export}

We first compare the propensities to export predicted by our model with the ones observed in the data. In particular, we determine the equilibria for each of the markets and each of the simulations at the observed values of the exogenous variables $\mathbf{X}_{m}$ and $\mathbf{Z}_{i m}$ and the estimated parameters. (This is an analogous exercise to the one we did in the previous section when we computed the percentage of multiple equilibria in the data.) To compute the propensity 
to export, we compute the ratio of firms exporting over the number of potential entrants. Thus, the propensity to export is an average propensity and it will vary by the number of potential entrants.

The first row of Table 8 presents the propensities to export that are computed in this fashion, separately for markets with $K_{m}=1, \ldots, K_{m}=7$ entrants. We find that the propensity to export is 0.964 (96.4 percent) in markets with one potential entrant, 0.588 in markets with two potential entrants, and that overall the propensity of each firm to export declines with the number of potential entrants. It is equal to 0.229 when there are seven potential entrants. Column (8) shows that the propensity to export when averaging across all markets is 0.388 .

We can compare these numbers with those that we observe in the data (reported in the second row of Table 8). With one potential entrant the propensity to export is 0.836 in the data, which is very close to our predicted value of 0.964 . With two potential entrants, the export propensity of each superstar is equal to 0.624 in the data, and the model predicts it to be 0.588 . Thus, we again conclude that the model does a fair job at fitting the data.

\subsection{Comparative Statics: Competitive Effects}

We begin our comparative statics exercise by investigating the role of competition as a determinant of superstar firms' export decisions. The third row of Table 8 shows the results when we set all the competitive effects $\left(\delta_{1}, \delta_{\text {Distance }}, \delta_{\mathrm{GDP}}\right.$, and $\left.\delta_{\text {Variety Destinations }}\right)$ equal to zero. Using the same simulations we used for the first two rows, we compute the equilibria for each market-simulation.

In markets with one potential entrant this exercise does not make any difference, which is obvious. In particular, the propensity to export is 0.963 . With more than one potential entrant, however, we find that the competitive effects are very important.

With two potential entrants, turning off the competitive effects would increase the export propensity from 0.588 to 0.943 , which is a dramatic increase. ${ }^{22}$ The competitive effects are crucial also in markets with more than two potential entrants. For example, if we set

\footnotetext{
${ }^{22}$ Notice that the new propensity to export is very close to the one we measure when there is only one potential entrant, which is a helpful cross-check on our methodological approach.
} 


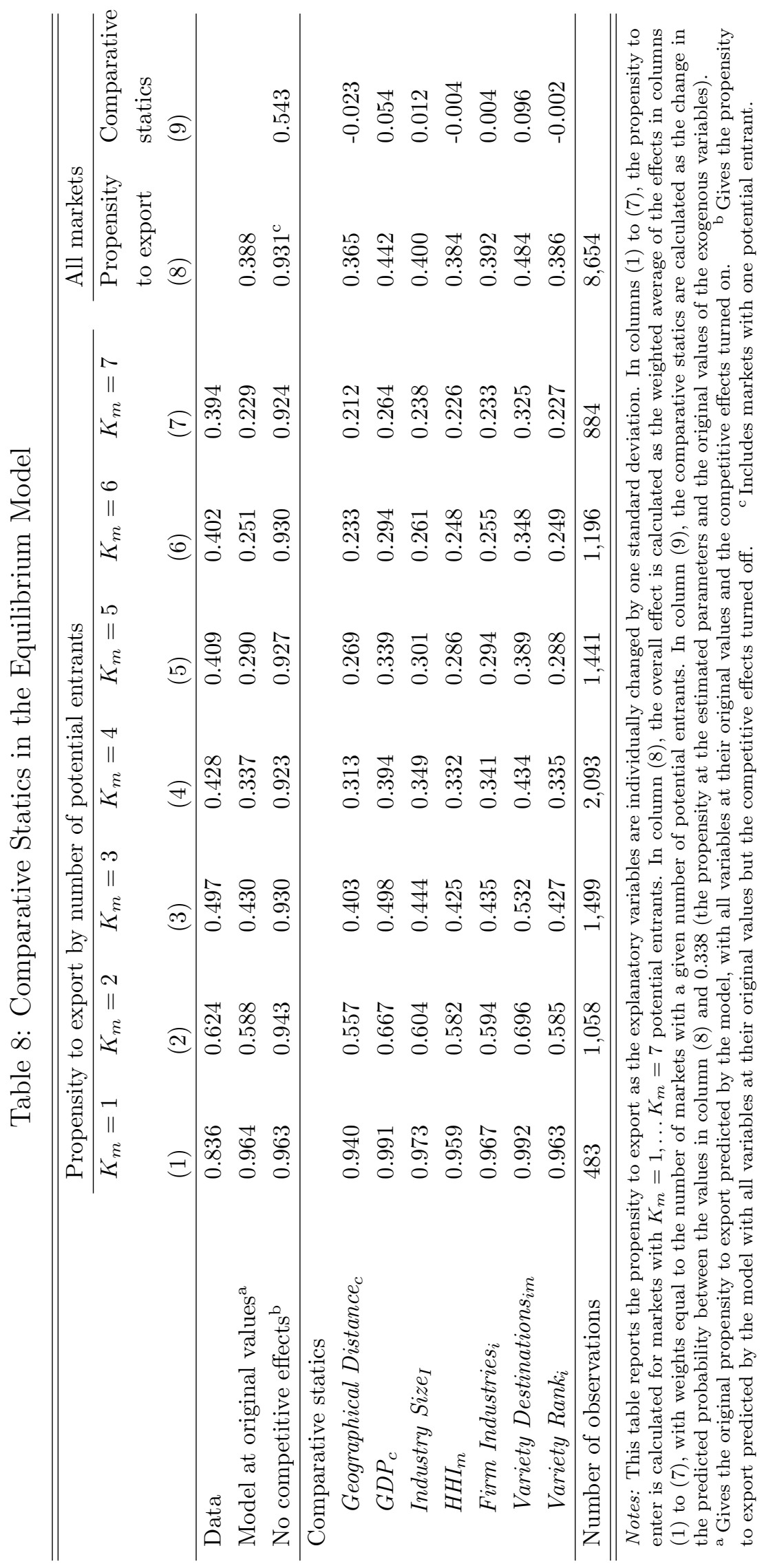


all competitive effects equal to zero, the export propensity increases from 0.430 to 0.930 in markets with three potential entrants; and from 0.337 to 0.923 in markets with four potential entrants. With seven potential entrants, we observe a change from 0.229 to 0.924 . Overall, without the competitive effects firms would be 53.4 percentage points more likely to export to a given market. Clearly, competition in export markets is an important determinant of export decisions. Notice that this number should be compared with the marginal effect of 19.18 percentage points in the probit model of Table 5. The effect that we find in the equilibrium model with strategic interactions is more than twice as large than in the single agent probit model.

\subsection{Comparative Statics: Exogenous Profit Determinants}

Next, to measure the economic effect of changes in the exogenous variables (except for tariffs, which are investigated in Section 7) we consider a one standard deviation increase in each variable, holding all other variables at their original values. For the individual variables, we have to change the variable for each firm at a time, and then take the average effect across all the potential firms in the market. We repeat the simulation exercise above and determine the new export propensities at the original estimates. Results are presented in Table 8.

Consider a one standard increase in the distance from Denmark. We now find that the export propensity with one potential entrant is 0.940 , with two potential entrants it is 0.557 , and with seven potential entrants it is 0.212 . When averaging across all markets the propensity to export is now 0.365 . The difference between 0.388 and 0.365 is -0.023 , which means that if distance increases by a one standard deviation, the propensity to export decreases, for each firm, by 2.3 percentage points. Notice that this is a change in the individual propensity to export, and the effect is larger when compounded over all the potential entrants. For example, the effect is -0.017 in markets with seven potential entrants. When compounded over all the seven potential entrants, this would imply that there is a 11.9 percentage points higher probability that at least one of the firms will not export into a market if distance increases by one standard deviation.

We find that one standard deviation increase in the GDP of the destination country is 
associated with a 5.4 percentage point increase in the propensity to export, a one standard deviation increase in industry size is associated with a 1.2 percentage point increase in the propensity to export, and a one standard deviation increase in the HHI is associated with a marginal decrease in the propensity to export.

We can conclude the analysis of exogenous changes in the market-specific variables by computing the probability that at least one firm will export after a one standard deviation increase in the geographical distance, the GDP, the industry size, and the HHI. We find those changes in the probabilities equal to, respectively, $-0.095,0.225,0.050$, and $-0.017 .^{23}$ These numbers are largely comparable to the ones in column (4) of Table 5, where we found the marginal effects of geographical distance, GDP, industry size, and the HHI, equal to, respectively, $-0.1566,0.1875,-0.0012$, and -0.0186 . Some of the differences may be explained by the different specification that we are running, since GDP and geographical distance are also interacting with the competitive effects in column (4) of Table 6.

Finally, we study changes in the export propensity for a one standard deviation increase in each of the firm-specific variables. In contrast to the changes in the market-specific variables which affect the profits of all the potential firms in a market, changes in the individual firmspecific variables only affect one firm at the time. We estimate that a one standard deviation increase in the variable Firm Industries $i$ yields an increase of 0.4 percentage points in the propensity to export, which is a magnitude close to the one we found in the probit model in Table 5. A one standard deviation in the variable Variety Rank $k_{i}$ is associated with a decrease of 0.2 percentage points in the propensity to export, which is again in the same order of magnitude as in Table 5.

We find that a one standard deviation increase in Variety Destinations $s_{i m}$ increases the propensity to export by 9.6 percentage points, which is a large effect, though smaller than the 26.37 percentage point effect that we found in Table 5. We interpret this as the result of the fact that the variable Variety Destinations attenuates the competitive effects, which makes the entry of a firm's competitor more likely.

\footnotetext{
${ }^{23}$ These numbers are derived by multiplying the ones in the last column of Table 8 by 4.16 , which is the weighted average number of potential entrants in the sample.
} 


\section{$7 \quad$ Policy Experiments}

Table 9 presents the results from two policy experiments. The first policy experiment consists of setting the binary variable Tariff $s_{m}$ equal to zero in all markets with positive tariffs and recomputing the equilibria to see how the propensity to export is affected. The results of this counterfactual exercise are presented in the top panel of Table 9. The second policy experiment consists of setting the binary variable Tariff $_{m}$ equal to one in those markets that do not have tariffs. The results for this counterfactual exercise are presented in the bottom panel of Table 9 .

For both policy experiments, we are particularly interested in how the strategic interaction between superstar exporters affects firms' export decisions after a trade policy change. For example, consider the case where trade is liberalized. If firms interact strategically, positive effects on profits due to trade liberalization are counter-balanced by negative effects due to competitor entry. In the following, we quantify by how much we overestimate the entry/exit response due to trade policy changes if we do not take the competitive effects into account.

\subsection{Eliminating Tariffs in Markets with Positive Tariffs}

Consider first the case of markets with positive tariffs. Out of the 3,601 export markets with positive tariffs, there are 198 markets with one potential entrant, 386 with two potential entrants, and so on. The first row of Table 9 shows the export propensity at the estimated parameters and the original values of the exogenous variables. We compute these propensities in the same fashion as we did in Table 8, except that we now take the average only across markets with positive tariffs. For example, before the policy change, the propensity to export is 0.534 in markets with two potential entrants, which is slightly lower than the value of 0.588 that we found for all the markets in Table 8.

Now, consider the counterfactual scenario where the tariffs are eliminated. The second row of Table 9 reports the new propensities to export. In markets with three potential entrants the propensity increases from 0.372 to 0.450 as trade becomes duty free. Similarly, in markets with seven potential entrants the propensity is now 0.247 , compared to 0.197 in 
the original situation with positive tariffs. In particular, if we consider the probability that at least one firm exports, this increases by 35 percentage points. ${ }^{24}$ When averaging across all markets, we find that the propensity to export increases from 0.334 to 0.406 if tariffs are eliminated. The difference is 7.2 percentage points, which is a large effect. Across all market structures, the probability that at least one firm exports increases by 30.5 percentage points. ${ }^{25}$ This is clearly a strong effect and confirms the importance of tariffs in determining the export market decisions of firms.

Next, we ask by how much we overestimate the entry response due to trade liberalization if the strategic interaction between superstar exporters is not taken into account. To address this line of inquiry, we perform the same counterfactual exercise but after having turned off the competitive effects. Essentially, we set $\delta_{1}, \delta_{\text {Distance }}, \delta_{\mathrm{GDP}}$, and $\delta_{\text {Variety Destinations }}$ equal to zero. We first compute the propensities to export at the original values of the exogenous variables, i.e., with positive tariffs. The results are presented in the third row of Table 9. As before, we find that the propensities to export are now very large, though different from those in Table 8 because the set of markets are different.

Consider now what happens to the export propensities if we eliminate the tariffs. We can compute the new equilibria in each market and we find that the average propensity to export increases from 0.876 to 0.967 , which corresponds to a 9.1 percentage point increase in the average probability that a firm exports. This is a larger number than the one we find when accounting for the competitive effects, which is 7.2 percentage points. When looking at the probability that at least one firm exports, we now find that this probability is $38.5(4.24 \times 0.091)$ percentage points higher after eliminating the tariffs. In contrast, our previous estimates where strategic interactions between firms were accounted for yielded a 30.5 percentage points increase (cf. above). Thus, the probability that at least one firm exports if tariffs are eliminated is overestimated by 8 percentage points when we do not take into account the strategic interaction between firms.

\footnotetext{
$24(0.247-0.197) \times 7$, which is equal to 35.

${ }^{25}$ This is calculated as the comparative statics effect across all markets (0.072) times the weighted average number of potential entrants in markets with positive tariffs, which is equal to 4.24 .
} 


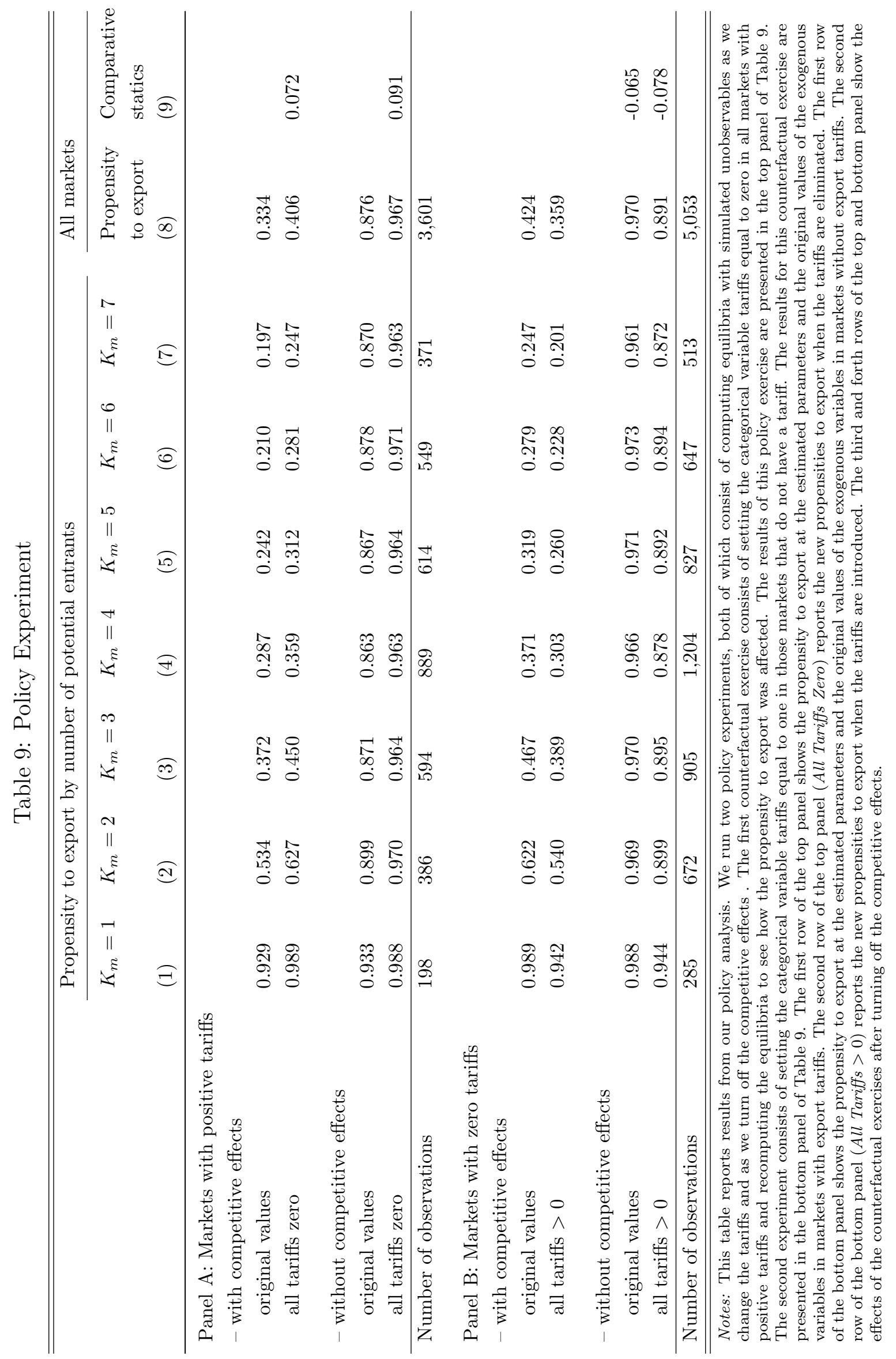




\subsection{Introducing Tariffs in Markets without Tariffs}

Our second policy experiment introduces tariffs to countries that currently have no tariffs. The exercise is similar to the one that we just described, except that now we look at a different set of markets. Thus, now we change the binary variable Tariff $s_{m}$ from 0 to 1 before recomputing the equilibria in each market-simulation.

The results of this counterfactual exercise are presented in the bottom panel of Table 9 . They show, for example, that introducing a tariff decreases the propensity to export from 0.371 to 0.303 in markets with four potential entrants. On average, the propensity to export drops from 0.424 to 0.359 , or by 6.5 percentage points. If we repeat this last exercise after turning off the competitive effects, we find that the average propensity of export would be predicted to drop by 7.8 percentage points.

When looking at the probability that at least one competitor stops exporting, we find that the probability without accounting for the competitive effects is equal to 44.94 percent $^{26}$; the same probability is equal to 37.44 percent when we account for the competitive effects. Thus, not accounting for the competitive effects would lead to overestimating the drop in the probability that at least one firm exports by 7.5 percentage points.

In summary, the strategic interaction between exporters implies that changes in tariffs have a less dramatic effect than what we would predict in single-firm models, where each firm acts independently of the other firms. We find the bias to be between 7.5 and 8 percentage points.

\section{Conclusion}

We study the determinants of export decisions by superstar firms, defined as firms with a share in industry-level exports of at least five percent. We model their export decisions as the result of a strategic game of entry, which we estimate adapting the methodology in Ciliberto \& Tamer (2009) to an international trade framework. We find that competitive effects have a large impact on firms' export decisions: in the absence of strategic interactions, firms would be 54.3 percentage points more like to export to a given market.

\footnotetext{
${ }^{26} 5.76 \times 7.8$, where 5.76 is the weighted average number of potential entrants in markets without tariffs.
} 
We also employ our model to analyze implications for trade policy. We show that failing to account for the strategic interaction among superstar exporters leads to: (i) overstating the probability that firms export to a market following tariff elimination by 8 percentage points; and, (ii) overstating the probability that firms would stop exporting to a market if tariffs were imposed by 7.5 percentage points.

Finally, we find that the competitive effects vary across firms and destinations. Negative competitive effects are larger in markets that are harder to enter, but smaller for firms with a larger export portfolio in terms of the export destinations. These heterogeneous competitive effects imply that there exist multiple equilibria, both in the identity and in the number of firms.

There are some limitations to our analysis. To begin with, we have modeled the strategic interaction among the firms as a static game. Our static model allows us to incorporate very general forms of heterogeneity among firms as well as multiple equilibria. To our knowledge, these are features that have not yet been modeled in dynamic games. We think of our approach as complementary to one where firms are modeled as playing a dynamic game, but where most of the heterogeneity across firms is necessarily assumed away.

Secondly, we have assumed that export decisions are independent across markets. For example, a Danish firms that is deciding whether to export to the Netherlands does not take into account its decision on whether to export to Belgium. This assumption is clearly at odds with the empirical evidence (see, e.g., Albornoz et al. (2012) and Morales et al. (2017)), but relaxing it is very difficult because it would require us to model firms' decisions as if they were building a network rather than one single link. We leave this challenging task to future work.

Finally, we have maintained that the Herfindahl-Hirschman Index (HHI) captures the role of non-Danish exporters in the import markets. Arguably, we would expect that the strategic interaction between non-Danish and Danish firms is more complex and nuanced than the one that can be captured by a single aggregate measure like the HHI. We think that there is a lot to benefit from merging firm-product level data from different countries, and we hope to see that direction pursued in future empirical work. 


\section{References}

Aitken, B., Hanson, G. H., \& Harrison, A. E. (1997). Spillovers, foreign investment, and export behavior. Journal of International Economics, 43(1-2), 103-132.

Albornoz, F., Pardo, H. F. C., Corcos, G., \& Ornelas, E. (2012). Sequential exporting. Journal of International Economics, 88(1), 17 - 31.

Audretsch, D., Prince, Y., \& Thurik, A. (1999). Do small firms compete with large firms? Atlantic Economic Journal, 27(2), 201-209.

Bekkers, E., \& Francois, J. (2013). Trade and industrial structure with large firms and heterogeneity. European Economic Review, 60(C), 69-90.

Bernard, A. B., Grazzi, M., \& Tomasi, C. (2015). Intermediaries in International Trade: Products and Destinations. The Review of Economics and Statistics, 97(4), 916-920.

Bernard, A. B., \& Jensen, J. B. (2004). Why Some Firms Export. The Review of Economics and Statistics, $86(2), 561-569$.

Bernard, A. B., Jensen, J. B., Redding, S. J., \& Schott, P. K. (2007). Firms in international trade. Journal of Economic Perspectives, 21 (3), 105-130.

Bernard, A. B., Redding, S. J., \& Schott, P. K. (2011). Multiproduct Firms and Trade Liberalization. The Quarterly Journal of Economics, 126(3), 1271-1318.

Berry, S. T. (1992). Estimation of a model of entry in the airline industry. Econometrica, $60(4)$, pp. 889-917.

Brander, J., \& Krugman, P. (1983). A 'reciprocal dumping' model of international trade. Journal of International Economics, 15(3), 313 - 321.

Brander, J. A. (1981). Intra-industry trade in identical commodities. Journal of International Economics, 11(1), $1-14$.

Brander, J. A., \& Spencer, B. J. (1985). Export subsidies and international market share rivalry. Journal of International Economics, 18(1), 83 - 100. 
Bresnahan, T. F., \& Reiss, P. C. (1990). Entry in monopoly market. The Review of Economic Studies, 57(4), 531-553.

Buono, I., \& Lalanne, G. (2012). The effect of the Uruguay round on the intensive and extensive margins of trade. Journal of International Economics, 86(2), 269-283.

Chernozhukov, H. H. T. E., Viktor (2007). Estimation and confidence regions for parameter sets in econometric models. Econometrica, 75, 1243-1284.

Chernozhukov, V., Hong, H., \& Tamer, E. (2007). Estimation and confidence regions for parameter sets in econometric models. Econometrica, 75(5), 1243-1284.

Choquette, E., \& Meinen, P. (2015). Export Spillovers: Opening the Black Box. The World Economy, 38(12), 1912-1946.

Ciliberto, F., Miller, A. R., Nielsen, H. S., \& Simonsen, M. (2016). Playing the fertility game at work : An equilibrium model of peer effects. International Economic Review, 57(3), $827-856$.

Ciliberto, F., \& Tamer, E. (2009). Market Structure and Multiple Equilibria in Airline Markets. Econometrica, $77(6), 1791-1828$.

Cohen, A., Freeborn, B., \& McManus, B. (2013). Competition and crowding out in the market for outpatient substance abuse treatment. International Economic Review, 54(1), $159-184$.

Das, S., Roberts, M. J., \& Tybout, J. R. (2007). Market entry costs, producer heterogeneity, and export dynamics. Econometrica, $75(3), 837-873$.

Debaere, P., \& Mostashari, S. (2010). Do tariffs matter for the extensive margin of international trade? an empirical analysis. Journal of International Economics, 81(2), 163 169.

di Giovanni, J., \& Levchenko, A. A. (2012). Country size, international trade, and aggregate fluctuations in granular economies. Journal of Political Economy, 120(6), 1083-1132. 
Dickstein, M., \& Morales, E. (2016). What do exporters know? Mimeo.

Eaton, J., Kortum, S., \& Kramarz, F. (2011). An Anatomy of International Trade: Evidence From French Firms. Econometrica, 79(5), 1453-1498.

Eaton, J., Kortum, S. S., \& Sotelo, S. (2012). International Trade: Linking Micro and Macro. NBER Working Papers 17864, National Bureau of Economic Research, Inc.

Eckel, C., \& Neary, J. P. (2010). Multi-Product Firms and Flexible Manufacturing in the Global Economy. Review of Economic Studies, 77(1), 188-217.

Feenstra, R. C., Luck, P. A., Obstfeld, M., \& Russ, K. N. (2014). In search of the Armington elasticity. Working Paper 20063, National Bureau of Economic Research.

Freund, C., \& Pierola, M. D. (2015). Export superstars. Review of Economics and Statistics, $97(5)$.

Guimbard, H., Jean, S., Mimouni, M., \& Pichot, X. (2012). MAcMap-HS6 2007, an exhaustive and consistent measure of applied protection in 2007. International Economics, 130, $99-121$.

Ho, K., \& Lee, R. S. (2017). Insurer competition in health care markets. Econometrica, $85(2), 379-417$.

Ho, K., \& Pakes, A. (2014). Hospital choices, hospital prices, and financial incentives to physicians. American Economic Review, 104(12), 3841-84.

Holmes, T. J. (2011). The diffusion of wal-mart and economies of density. Econometrica, $79(1), 253-302$.

Holmes, T. J., \& Stevens, J. J. (2014). An alternative theory of the plant size distribution, with geography and intra- and international trade. Journal of Political Economy, 122(2), pp. 369-421.

Jia, P. (2008). What happens when wal-mart comes to town: An empirical analysis of the discount retailing industry. Econometrica, 76 (6), 1263-1316. 
Koenig, P., Mayneris, F., \& Poncet, S. (2010). Local export spillovers in France. European Economic Review, 54(4), 622-641.

Koska, O. A., \& Stähler, F. (2014). Trade and imperfect competition in general equilibrium. Journal of International Economics, 94, 157-168.

Lawless, M. (2009). Firm export dynamics and the geography of trade. Journal of International Economics, $77(2), 245-254$.

Manski, C. F. (1993). Identification of endogenous social effects: The reflection problem. The Review of Economic Studies, 60(3), 531-542.

Mayer, T., Melitz, M. J., \& Ottaviano, G. I. P. (2014). Market Size, Competition, and the Product Mix of Exporters. American Economic Review, 104(2), 495-536.

Mazzeo, M. (2002). Product choice and oligopoly market structure. RAND Journal of Economics, 33, 1-22.

Melitz, M. J. (2003). The Impact of Trade on Intra-Industry Reallocations and Aggregate Industry Productivity. Econometrica, 71(6), 1695-1725.

Morales, E., Sheu, G., \& Zahler, A. (2017). Extended gravity. Mimeo.

Neary, J. P. (2010). Two and a Half Theories of Trade. The World Economy, 33(1), 1-19.

Neary, P. (2015). International Trade in General Oligopolistic Equilibrium. Economics Series Working Papers 769, University of Oxford, Department of Economics.

Nguyen, D. X. (2012). Demand uncertainty: Exporting delays and exporting failures. Journal of International Economics, 86(2), 336-344.

Parenti, M. (2013). Large and small firms in a global market: David vs. Goliath. CORE Discussion Papers 2013058, Université catholique de Louvain, Center for Operations Research and Econometrics (CORE).

Rennhoff, A. D., \& Owens, M. F. (2012). Competition and the Strategic Choices of Churches. American Economic Journal: Microeconomics, 4(3), 152-170. 
Roberts, M. J., \& Tybout, J. R. (1997). The Decision to Export in Colombia: An Empirical Model of Entry with Sunk Costs. American Economic Review, 87(4), 545-64.

Tamer, E. (2003). Incomplete Simultaneous Discrete Response Model with Multiple Equilibria. Review of Economic Studies, 70(1), 147-165.

World Trade Organization (2008). World Trade Report: Trade in a Globalizing World. Geneva: World Trade Organization. 


\section{A Data Appendix}

\section{A.1 Construction of Sample}

Our starting point is the universe of export transactions by firm, destination and product. We aggregate products up to the NACE four-digit industry level in order to account for competition between firms producing products that are close substitutes. We focus on a cross section for the year 2007.

We define superstar firms based on their share in industry-wide exports, and purely domestic firms are therefore by definition excluded from the sample. However, this choice is not very restrictive since firms that only sell their output domestically are typically smaller firms. We also exclude wholesalers, retailers and other non-manufacturing firms, since these firms' exporting behavior differs significantly from the one of manufacturing firms; see, e.g., Bernard et al. (2015). However, in Appendix B we discuss results where we (i) account for competition from non-manufacturing firms, or (ii) restrict the sample to industries where manufacturing firms dominate overall exports.

\section{Selection of Markets}

As discussed in the main text, we restrict the sample to markets which could potentially be served by the firms in our sample. Hence, we keep only markets that were served at least twice over the last five years. Our final sample covers 72 percent of overall Danish manufacturing exports.

Figure A.1 further describes the sample composition in terms of destinations and industries. In some of the most export intensive industries - such as NACE 2651 ("Manufacture of instruments and appliances for measuring, testing and navigation") and NACE 2110 ("Manufacture of basic pharmaceutical products") - almost all destinations are judged to be attractive (according to the criteria mentioned above), and hence included in the sample; see Figure 1(a). Some other industries - such as NACE 2363 ("Manufacture of ready-mixed concrete") - are little export-oriented, and our sample selection criteria lead us to exclude many destination markets. Similarly, in the most popular destinations (Germany and Sweden), we observe more than 200 industries; see Figure 1(b). However, on average, we only 


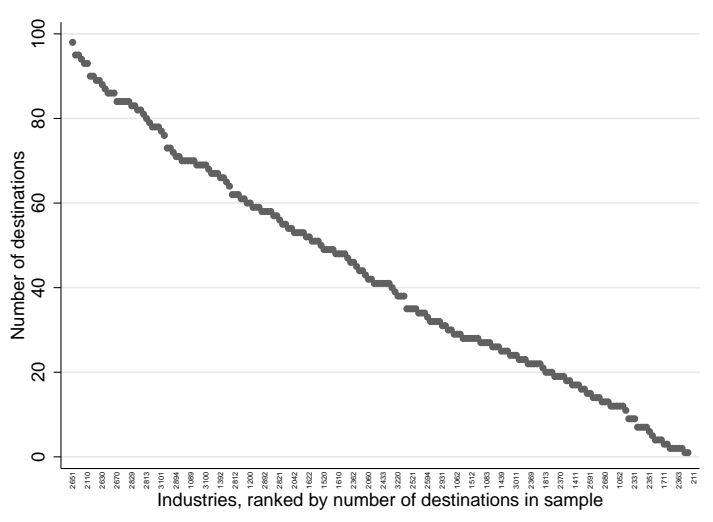

(a) Number of Destinations by Industry

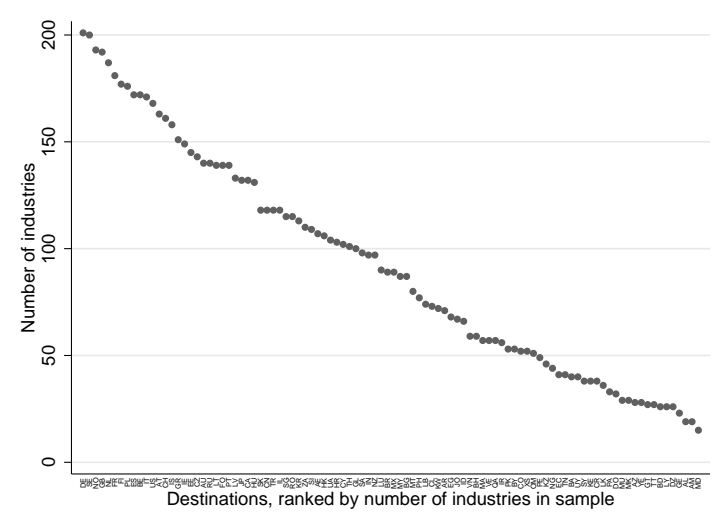

(b) Number of Industries by Destination

Figure A.1: Sample Composition: Destinations and Industries

include 92 industries per destination.

\section{Persistence in Superstar Status}

Varieties are included in the sample of superstar exporters if they have a share in industrywide exports in 2007 of at least 5 percent. Here, we document that firms do not become superstars overnight, but rather that their is a large extent of persistence in superstar status. In particular, 77 percent of superstars in 2007 were already superstars in 2006; and 81 percent of superstars in 2006 were still superstars in 2007. Moreover, out of those varieties that became superstars from 2006 to 2007, the average market share in 2006 (i.e., the year before becoming superstar) was 2.4 percent. Thus, even those varieties that passed the 5 percent threshold from 2006 to 2007 typically had a considerable share in industry-wide exports already in the pre-sample year.

\section{A.2 Discretization}

In order to estimate the equilibrium model in Section 5, we need to discretize each of our control variables. We do so by first standardizing the variable, i.e., subtracting the mean and dividing by the standard deviation. Subsequently, we divide the standardized variable into unit intervals. We then represent values that fall into a specific interval by the mid point of this interval. We check the plausibility of the discretization procedure by comparing probit results for the standardized and the discretized variables, and find that estimated effects are 
qualitatively and quantitatively unaffected by the discretization.

\section{A.3 Computational Details}

We use 100 simulations for each of the four errors, which are drawn independently from four standard normal distributions and then added together. The simulated errors are then used, together with the original values of the exogenous variables, and parameter guesses, to compute the profits of each potential entrant in a market. Based on the profits, we determine the equilibria in each market. The lower bounds in Equation (3) are constructed based on all the market observations where there is a unique equilibrium. The upper bounds are constructed based on all the market observations where there are multiple equilibria. Then, we compute the distance function described in Section 2.2. We continue to search over different parameter guesses until we minimize the distance function.

The minimization is run using a combination of different algorithms in Matlab. First, we use the package simulannealbnd, which is a simulated annealing solver for derivative-free optimization algorithm. Then, we use the package patternsearch, which is an algorithm that uses a pattern search method that implements a minimal and maximal positive basis pattern. Finally, we use a standard Nelder-Mead approach as well.

We start our computational analysis from the simplest model (Column 1 in Table 6) using more than 20 different starting values. The choice of the starting values is informed by the results from the probit regressions. For example, we choose positive initial parameter values for the GDP, and negative for the geographical distance.

In addition, because all of our variables are standardized (except the binary variable for the tariffs), we can limit our search of the parameters over the intervals $[-3,3]$ for the exogenous variables. After one day of search, we check the best function value to that point, and we start additional searches from the parameter associated to that function value and from multiple other starting values that are built from small variations of the individual parameters where the function had been minimized.

After finding the minimum for Column (1) of Table 6, we move in sequence to the other Columns, adding each time more parameters to be estimated. 
Table B.1: Summary Statistics for Robustness Analysis

\begin{tabular}{|c|c|c|c|}
\hline & Mean & Std dev & 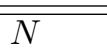 \\
\hline \multicolumn{4}{|l|}{ Competitor-specific variables $\mathbf{Z}_{i m}$} \\
\hline Number of employees ${ }_{i}$ & 585.0 & 1,340 & 36,949 \\
\hline Labor productivity $_{i}$ & 658,260 & 322,641 & 36,788 \\
\hline \multicolumn{4}{|l|}{ Market-specific variables $\mathbf{X}_{m}$} \\
\hline Fringe Competitors $_{m}$ & 9.314 & 18.57 & 37,198 \\
\hline Non-Manufacturing Competitors ${ }_{m}$ & 13.91 & 31.85 & 37,198 \\
\hline
\end{tabular}

Notes: The table reports summary statistics for additional control variables included in our robustness analysis. All variables are included in logs in the estimation.

We find the minimum of the objective function in approximately three days using as many as twenty-five individual computers at the same time, which were run separately. The computer that we use are HP DL580 Gen9 - E7-4830v3 4 CPU server, with Intel Xeon 2.1Ghz/12-core/30MB/115W processors.

\section{B Robustness Analysis}

In this section, we report several sets of robustness checks. First, we extend our empirical model to include additional control variables. Secondly, we analyze the robustness of our findings to alternative ways of constructing our sample. Ideally, all robustness checks should have been performed using the equilibrium model, but this proves computationally burdensome. We thus resort to the (single equation) probit model in this section. Importantly, we find that results are both qualitatively as well as quantitatively robust to those reported in Section 4 .

\section{B.1 Additional Control Variables}

This section analyzes the robustness to adding further control variables. Table B.1 reports summary statistics for all additional variables and Table B.2 reports parameter estimates from the probit model.

We first extend the set of variables included in the vector $\mathbf{Z}_{i m}$. In particular, we allow export participation to be related to firm size and labor productivity, as measured by the number of employees and value added per employee, respectively. Firm size and productivity are standard controls in the empirical trade literature; see e.g. Roberts \& Tybout (1997) 
and Bernard \& Jensen (2004). In fact, models with heterogeneous firms (e.g., Melitz (2003)) predict that larger, more productive firms are more likely to export to a given market.

Column (1) of Table B.2 broadly confirms these predictions. Firm size (as measured by the number of employees) enters positively as expected. Firm productivity is the main driver of export participation in empirical studies building on Melitz (2003). However, we find that productivity does not affect the probability to export. On closer inspection, this result is driven by a high correlation of productivity with a firm's industry scope.

Next, we add further variables to the vector of market-specific determinants of profits, $\mathbf{X}_{m}$. In particular, we include the variable Fringe Competitors ${ }_{m}$, which is defined as the number of fringe firms entering a given market $m \cdot{ }^{27}$ Column (2) of Table B.2 shows that the coefficient on Fringe Competitors $s_{m}$ is positive. Thus, in contrast to the negative effect of other superstar competitors, fringe competitors actually have a positive effect on the export decisions of the superstars. This finding is interesting because it confirms that negative competitive effects are only relevant for large firms which have the capability of affecting the market outcome. Moreover, it is consistent with the results on positive informational spill-overs in the trade literature (see, e.g., Aitken et al. (1997), Koenig et al. (2010) and Choquette \& Meinen (2015)).

In column (3), we investigate the effects of competition from non-manufacturing firms. The variable Non-Manuf. Competitors $s_{m}$ is defined as the number of non-manufacturing firms entering a given market $m .^{28}$ We find that the presence of non-manufacturing firms also has a positive effect on the export probability of the superstars. Thus, similar to the case of fringe firms, the net effect between negative competitive effects and informational spillovers is positive if a firm's non-manufacturing competitors enter a market.

Finally, we want to substantiate that our focus on manufacturing firms does not affect our estimates of the competitive effect. We thus estimate regressions where we restrict the sample to industries where manufacturing firms account for the majority of exporters (defined as 50 percent or 70 percent); see columns (4) and (5) of Table B.2. Results for these restricted samples are comparable to those reported in Table 5.

\footnotetext{
${ }^{27}$ This variable is included in logs in the empirical model.

${ }^{28}$ This variable is included in logs in the empirical model.
} 


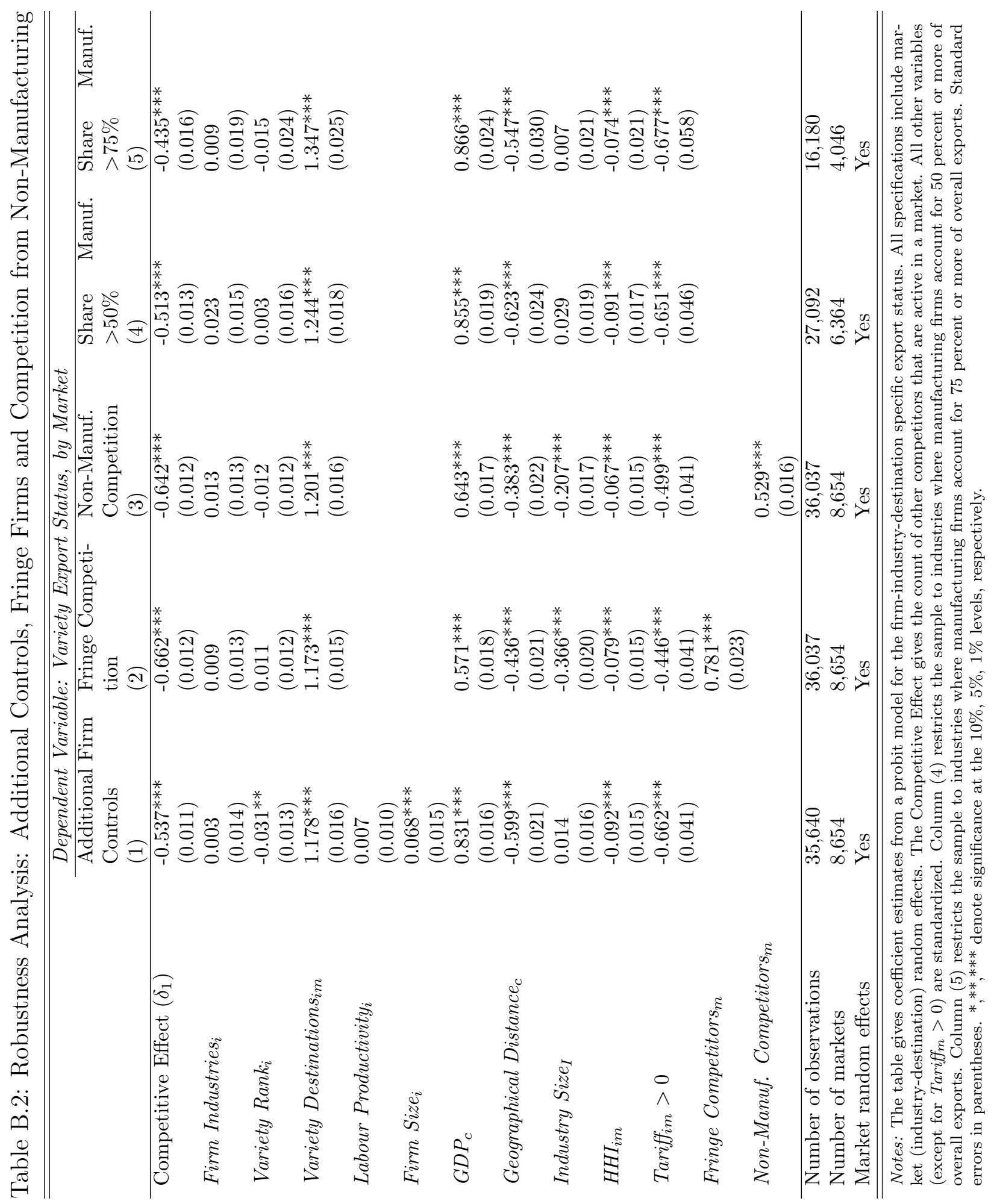


Thus, across all specifications reported in Table B.2, our estimates of the effect of interest (the competitive effect between superstar exporters) remain unaffected.

\section{B.2 Extending the Sample}

In this section, we report a number of robustness checks regarding the construction of the sample.

\section{Robustness to Alternative Years}

Our sample is a cross-section for the year 2007. The choice of year is mainly driven by data availability regarding the tariff data. Specifically, the CEPII (Guimbard et al., 2012) provides custom-made information on applied, preferential tariffs for the year 2007 for a large number of importing countries. Importantly, non-ad valorem tariffs have already been transformed into ad-valorem equivalents by these authors. Nevertheless, it is important to establish that our results are not specific to the (pre-crisis) year 2007.

We thus estimate the probit model on data from different years. Specifically, columns (1) and (2) of Table B.3 report results for the years 2005 and 2006, respectively. Note that specifications do not include tariffs and the HHI, since these variables were not readily available for those years. The parameter estimate for the competitive effect is negative and comparable in magnitude to the one reported in Table 5.

\section{Including More Markets}

In the main text, we have restricted the sample to the top 100 destinations. In column (3) of Table B.3 we show results where all destinations are included, as long as the criterion regarding a market being 'attractive' (i.e. having been served at least twice over the last five years) is still fulfilled. As can be seen, the sample size only increases slightly, implying that the restriction to the top 100 destinations is not very strict. Moreover, results on the sign and size of the competitive effect are again confirmed. 
Table B.3: Robustness to Extending the Sample

\begin{tabular}{|c|c|c|c|c|c|}
\hline & $(1)$ & $(2)$ & $(3)$ & $(4)$ & \\
\hline & Year 2005 & Year 2006 & $\begin{array}{l}\text { All Destina- } \\
\text { tions }\end{array}$ & $\begin{array}{l}\text { Superstar } \\
\text { percent }\end{array}$ & 10 \\
\hline Competitive Effect $\delta_{1}$ & $\begin{array}{l}-0.503^{* * *} \\
(0.011)\end{array}$ & $\begin{array}{l}-0.549^{* * *} \\
(0.011)\end{array}$ & $\begin{array}{l}-0.514^{* * *} \\
(0.011)\end{array}$ & $\begin{array}{l}-0.615^{* * *} \\
(0.019)\end{array}$ & \\
\hline Firm Industries $_{i}$ & $\begin{array}{l}0.051^{* * *} \\
(0.012)\end{array}$ & $\begin{array}{l}0.051^{* * *} \\
(0.013)\end{array}$ & $\begin{array}{l}0.050^{* * *} \\
(0.012)\end{array}$ & $\begin{array}{l}0.039 * * \\
(0.018)\end{array}$ & \\
\hline Variety Rank $_{i}$ & $\begin{array}{l}0.009 \\
(0.012)\end{array}$ & $\begin{array}{l}-0.013 \\
(0.012)\end{array}$ & $\begin{array}{l}-0.019^{*} \\
(0.011)\end{array}$ & $\begin{array}{l}-0.009 \\
(0.016)\end{array}$ & \\
\hline Variety Destinations ${ }_{i m}$ & $\begin{array}{l}1.142^{* * *} \\
(0.015)\end{array}$ & $\begin{array}{l}1.099^{* * *} \\
(0.015)\end{array}$ & $\begin{array}{l}1.107^{* * *} \\
(0.014)\end{array}$ & $\begin{array}{l}1.162^{* * *} \\
(0.020)\end{array}$ & \\
\hline$G D P_{c}$ & $\begin{array}{l}0.725^{* * *} \\
(0.015)\end{array}$ & $\begin{array}{l}0.707^{* * *} \\
(0.015)\end{array}$ & $\begin{array}{l}0.809^{* * *} \\
(0.015)\end{array}$ & $\begin{array}{l}0.626^{* * *} \\
(0.017)\end{array}$ & \\
\hline Geographical Distance $_{c}$ & $\begin{array}{l}-0.779^{* * *} \\
(0.015)\end{array}$ & $\begin{array}{l}-0.759^{* * *} \\
(0.015)\end{array}$ & $\begin{array}{l}-0.790^{* * *} \\
(0.015)\end{array}$ & $\begin{array}{l}-0.691^{* * *} \\
(0.018)\end{array}$ & \\
\hline${\text { Industry } \text { Size }_{I}}$ & $\begin{array}{l}-0.033^{* *} \\
(0.015)\end{array}$ & $\begin{array}{l}-0.037^{* *} \\
(0.015)\end{array}$ & $\begin{array}{l}-0.023 \\
(0.014)\end{array}$ & $\begin{array}{l}-0.148^{* * *} \\
(0.017)\end{array}$ & \\
\hline Number of observations & 37,893 & 35,566 & 40,247 & 20,517 & \\
\hline Number of markets & 9,183 & 8,985 & 9,670 & 8,732 & \\
\hline Market random effects & Yes & Yes & Yes & Yes & \\
\hline
\end{tabular}

Notes: The table gives coefficient estimates from a probit model for the firm-industry-destination specific export status. All specifications include market (industry-destination) random effects. The Competitive Effect gives the count of other competitors that are active in a market. All other variables (except for Tariff $m>0$ ) are standardized. Standard errors in parentheses. ${ }^{*}, * *, * * *$ denote significance at the $10 \%, 5 \%, 1 \%$ levels, respectively.

\section{Applying a Stricter Superstar Definition}

We have defined superstars as firms that, within an industry, account for 5 percent or more of overall exports. The idea is that only sufficiently large firms have the market power to influence market outcomes. The 5 percent threshold might still seem too low in this respect, and we thus as a robustness check constrain the set of superstars to firms with a share in overall industry-wide exports of at least 10 percent. Results, reported in column (4) of Table B.3, confirm that the estimated competitive effect remains largely stable even with this alternative superstar definition. 


\section{Economics Working Papers}

2016-08: $\quad$ Rune V. Lesner: The Long-Term Effect of Childhood Poverty

2016-09: $\quad$ Sylvanus Kwaku Afesorgbor: Economic Diplomacy in Africa: The Impact of Regional Integration versus Bilateral Diplomacy on Bilateral Trade

2016-10: John Kennes and Daniel le Maire: On the equivalence of buyer and seller proposals within canonical matching and pricing environments

2016-11: Ritwik Banerjee, Nabanita Datta Gupta and Marie Claire Villeval: The Spillover Effects of Affirmative Action on Competitiveness and Unethical Behavior

2017-01: Rasmus Landersø, Helena Skyt Nielsen and Marianne Simonsen: How Going to School Affects the Family

2017-02: Leslie S. Stratton, Nabanita Datta Gupta, David Reimer and Anders Holm: Modeling Enrollment in and Completion of Vocational Education: the role of cognitive and non-cognitive skills by program type

2017-03: Nabanita Datta Gupta, Anton Nielsson and Abdu Kedir Seid: Shortand Long-Term Effects of Adolescent Alcohol Access: Evidence from Denmark

2017-04: Michael Koch and Marcel Smolka: Foreign Ownership and Skill-biased Technological Change

2017-05: Mette Trier Damgaard and Helena Skyt Nielsen: Nudging in education: A survey

2017-06: Alexander K. Koch and Julia Nafziger: Motivational Goal Bracketing: An Experiment

2017-07: Ina C. Jäkel Allan Sørensen: Exporter Price Premia?

2017-08: Marianne Simonsen, Lars Skipper and Niels Skipper: Piling Pills? Forward-Looking Behavior and Stockpiling of Prescription Drugs

2017-09: Federico Ciliberto and Ina C. Jäkel: Superstar Exporters: An Empirical Investigation of Strategic Interactions in Danish Export Markets 